Report No. BMI-1312

UC-25 Metallurgy and Cexamics

(TID $-4500,14$ th Ed.)

Contract No. W-7405-eng-92

GAS-PRESSURE BONDING OF FLAT-PLATE FUEL ASSEMBLIES

by

Stan J. Paprocki

Edwin S. Hodge

Charles B. Boyer

Ralph W. Getz

January 20,1959

BATTELLE MEMORIAL INSTITUTE

$505 \mathrm{King}$ Avenue

Columbus 1, Ohio 


\section{DISCLAIMER}

This report was prepared as an account of work sponsored by an agency of the United States Government. Neither the United States Government nor any agency Thereof, nor any of their employees, makes any warranty, express or implied, or assumes any legal liability or responsibility for the accuracy, completeness, or usefulness of any information, apparatus, product, or process disclosed, or represents that its use would not infringe privately owned rights. Reference herein to any specific commercial product, process, or service by trade name, trademark, manufacturer, or otherwise does not necessarily constitute or imply its endorsement, recommendation, or favoring by the United States Government or any agency thereof. The views and opinions of authors expressed herein do not necessarily state or reflect those of the United States Government or any agency thereof. 


\section{DISCLAIMER}

Portions of this document may be illegible in electronic image products. Images are produced from the best available original document. 


\section{TABLE OF CONTENTS}

$\underline{\text { Page }}$

ABSTRACT . . . . . . . . . . . . . . . . . . . . . 11

INTRODUCTION . . . . . . . . . . . . . . . . . . . . . . . . 1

EXPERIMENT AL PROCEDURES • . . . . . . . . . . . . . . 3

Gas-Pressure-Bonding Equipment . . . . . . . . . . . . . 3

Fabrication of Containers for Pressure Bonding . . . . . . . . 7

Fabrication of Components for Pressure Bonding . . . . . . . . 7

Cleaning Techniques. . . . . . . . . . . . . . . . . . 99

Assembly and Evacuation of Assemblies for Pressure Bonding . . . 13

GAS-PRESSURE-BONDING RESULTS . • . • . . . . . . . . . . 15

Feasibility Study . . . . . . . . . . . . . . . . . 15

Surface-Preparation Investigation . . . . . . . . . . . . 17

Development of Gas-Pressure-Bonding Technique for Preparing

2 by 2 by 20 -In. Flat-Plate As semblies . . . . . . . . . . 31

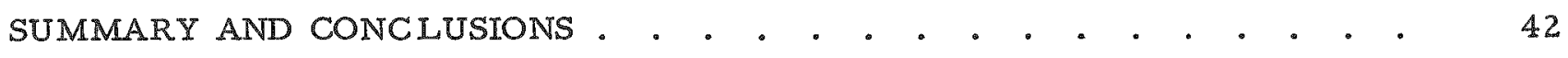

ACKNOWLEDGMENT • . . . . . . . . . . . . . . . . . . . 43

REFERENCES . . . . . . . . . . . . . . . . . . . . . . 4 43

APPENDIX

EVALUATION OF PRESSURE BONDED SUBASSEMBLIES - . . . . . . A-1 


\title{
GAS-PRESSURE BONDING OF FLAT-PLATE FUEL ASSEMBLIES
}

Stan J. Paprocki, Edwin S. Hodge, Charles B. Boyer, and Ralph W. Getz

\begin{abstract}
Subscale flat-plate fuel subassemblies measuring up to 2 by 2 by 20 in., incorporating 16 Zircaloy-2oclad uranium-zirconium fuel plates and 15 coolant channels, were successfully fabricated by the gas-pressure-bonding process. Autoclave design, specimen-container configuration, and the design and preparation of specimen components were among the problems studied.
\end{abstract}

Uneven heating of the bonding specimen, caused in part by convective heat transfer, was minimized by developing a special four-element muffle-iype resistance heater for the autoclave and by filling void space between the specimen and heater with copper plates and sand. Nith this arrangement there was only a 10 to $15 \mathrm{~F}$ variation over a $36-i n$. zone at $1500 \mathrm{~F}$. A Type 304 stainless specimen container design, resembling in cross section a swastika, allow'ed distortion-free bonding of specimens without supplementary jigging. The practicality of building up an entire assembly from simple, rectangular pieces was demonstrated. This technique makes it easier to maintain the close dimensional tolerances required for fabrication of flat-plate assemblies and eliminates the expensive machining required to produce one-piece picture frames. Flat Ti-Namel stock inserted between the Zircaloy-2alad fuel plates during assembly of the components was removed after bonding was completed by acid etching to form the coolant channels. Chromium plating the Ti-Namel prevented reaction with the Zircaloy-2. In studies of surface preparation, it was found that removing 2 to 3 mils of surface by machine belt abrading of the components with 60-grit SiC produced consistent bonding. Bonding of the assemblies at $1550 \mathrm{~F}$ for $4 \mathrm{hr}$ under a helium pressure of $10,000 \mathrm{psi}$ produced excellent results.

\section{INTRODUCTION}

An investigation has been made of the simultaneous cladding and bonding of flatplate Zircaloy-2-clad uranium-zirconium fuel assemblies utilizing the gas-pressurebonding technique. This technique involves the fabrication of the components to be bonded to final size, followed by cleaning and assembly of these components into a container. The container is then evacuated, sealed, and placed inside a high-pressure cold-wall autoclave and subjected to a high inert-gas pressure at an elevated temperature. The pressure is uniformly transmitted through the container, forcing the components into intimate contact. The pressure and temperature are maintained a sufficient length of lime to allow for the diffusion bonding of all the component interfaces to form an integral assembly.

Conventionally, flat-plate fuel assemblies are prepared by first fabricating the individual fuel elements and then joining them by brazing or welding to form multiplate structures. The many operations involved in this process increase both the cost and the problems of quality control in fuel-assembly fabrication. Successful application of the one-step gas-pressure-bonding technique to full-as sembly fabrication would offer improvement in both of these areas. 
Investigations prior to the present program in which gas-pressure bonding was studied for application in the fabrication of other types of fuel elements showed that the technique had excellent promise. Bonding was accomplished in the se early studies at relatively low pressures and temperatures and required long periods of time at temperature. In subsequent research, much of the development effort was directed toward shortening the bonding cycle by raising the temperature-pressure capacity of the autoclave. A new autoclave concept involving internal heating was evolved. Continued progress with the technique prompted the initiation of two additional programs: a project concerned with the cladding of delta-phase zirconium hydride with stainless steel, and a concurrent study of the feasibility of producing in a single bonding operation multiplate fuel assemblies. Through the refinements in autoclave design made during these programs, it is now possible to bond at temperatures up to $2400 \mathrm{~F}$ with pressures up to 10,000 psi for variable times. A report describing the program on the cladding of zirconium hydride has been issued. (1) The results of the feasibility study on flatplate fuel assemblies are contained in the present report along with the results of a subsequent program that extended the research to the development of methods for producing full-size assemblies by the pressure-bonding technique.

In addition to the equipment improvements, the feasibility study was concerned with the design and fabrication of suitable containers for holding the assemblies during pressure bonding, the design and fabrication of the individual components for the assemblies, the development of optimum cleaning and surface-preparation techniques for the components, and the investigation of the effects of various assembly and evacuation procedures. Subscale flat-plate assemblies 1 by 1 by 3 in. and 1 by 1 by 6 in., incorporating five fuel plates, were produced during the feasibility study. Ti-Name1 strips were positioned between the fuel plates to serve as supports during the bonding operation, and were later dissolved with acid to form the coolant channels. The feasibility of building up entire assemblies from simple rectangular pieces was demonstrated. The feasibility study established that the gas-pressure bonding process was a practicable method for preparing complete subscale assemblies without the intermediate step of making individual fuel elements. The investigation was then directed toward a more extensive development program on larger subscale assemblies. Investigations of the gas-pressure-bonding technique to further reduce costs associated with the production of integral assemblies, equipment problems, and associated metallurgical problems were included in this program.

A number of subscale flat-plate as semblies measuring 2 by 2 by 6 in. incorporating 16 fuel plates with 15 channels were pressure bonded and evaluated to determine if the use of pieced components was feasible.

Three 2 by 2 by 20 -in. subscale flat-plate assemblies incorporating 16 fuel plates with 15 channels were fabricated toward the end of the study. Considerable difficulty was encountered in obtaining a uniform heat zone during the pressure bonding of the first 20-in.-long assembly. After equipment modification, the final assembly was pressure bonded with a helium pressure of 10,000 psi for $4 \mathrm{hr}$ at $1550 \mathrm{~F}$, with only a $10 \mathrm{~F}$ temperature variation over the length of the specimen. Metallographic examination of sections taken from both ends of this assembly revealed that very good Zircaloyto-Zircaloy bonds were obtained. Excellent dimensional control was achieved with no bow or camber. No external jigging was necessary to obtain maximum dimensional control during the bonding of this specimen. The results of this study revealed that it is feasible to prepare full-scale as semblies by this technique.

(1) References at end. 
The feasibility study and the initial phases of the subsequent study were conducted using reactor-grade inert-atmosphere arc-melted Zircaloy-2 for cladding material. In the latter studies, it was suggested by the Core Engineering Group at Bettis that vacuum-arc-melted Zircaloy -2 be investigated for use in this program, because more consistent bonding has been achieved with the vacuum-melted Zircaloy-2. A small amount of double vacuum-melted Zircaloy -2 was supplied by Bettis for evaluation tests. Evaluation of pressure-bonded test specimens indicated that the vacuum-melted material appeared to bond as well as the atmosphere-melted material and was less sensitive to minor changes in surface preparation than atmosphere-melted material.

The core material for the assemblies in this study was either zirconium-22 or $-5.5 \mathrm{w} / 0$ uranium. The latter alloy was used in all except the initial feasibility study. The zirconium $-5.5 \mathrm{w} / 0$ uranium was prepared according to specifications followed by Bettis in fuel-element production.

Ti-Namel, which is an enameling grade of titanium-killed mild steel, was employed as channel inserts and backup plates for the assemblies. Extensive diffusion of iron into the Zircaloy -2 resulted when bonding at temperatures around $1550 \mathrm{~F}$, requiring the use of chromium-plated Ti-Namel components. All Ti-Namel was obtained from Bettis.

Type 304 stainless steel sheet material approximately $0.018 \mathrm{in.} \mathrm{thick} \mathrm{was} \mathrm{used}$ for the sides and $0.080 \mathrm{in}$. thick was used for the end plugs of the containers. Evacuation tubes for the containers were cut from Type 304 stainles steel seamless tubing.

EXPERIMENTAL PROCEDURES

Gas-Pressure-Bonding Equipment

The pressure-bonding equipment utilized in this study incorporated several unique features. The initial phases of the investigation were conducted in a pressure vessel procured from the Autoclave Engineering Company. A sectional view of a slightly modified model of this autoclave unit is shown in Figure 1. The vessel body was machined from a Type 410 stainless steel for ging and is $61-3 / 4$ in. long, 9 in. in ID, and 13.650 in. in OD. A tight seal is maintained at both ends of the vessel by employing heads which utilize a modified Bridgman closure. (2) This is an axial type of self-sealing closure which applies the line-contact principle. (3)

This unit has pressure-sealed openings for electrical and the rmocouple leads, a pressure inlet, a vacuum outlet, a pressure-control outlet, and a rupture safety-disk assembly. The vessel was designed to operate at a pressure of 10,000 psi with a wall temperature of $700 \mathrm{~F}$. Temperatures of $1925 \mathrm{~F}$ at gas pressures of 10,000 psi have been maintained for periods of $3 \mathrm{hr}$ with the outside wall of the autoclave not exceeding $250 \mathrm{~F}$.

Toward the end of this study, two additional cold-wall autoclave units were placed in operation. The autoclave vessels were also procured from the Autoclave Engineering Company. The units are basically the same as the first cold-wall autoclave and were 

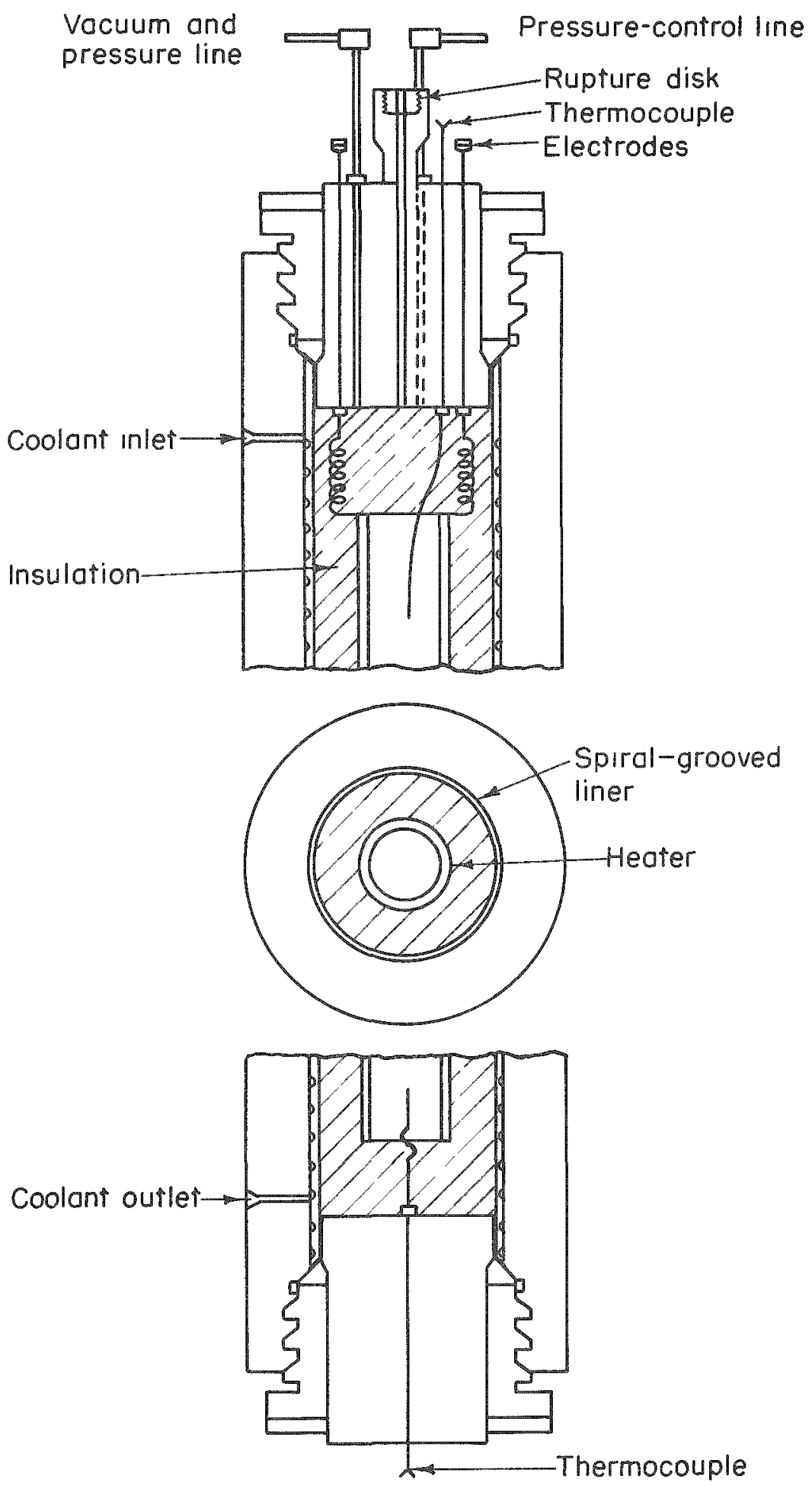

A 27437

FIGURE 1. SECTIONAL VIEW OF A HIGH-PRESSURE COLD-WALL AUTOCLAVE WITH SPIRAL-GROOVED LINER 
designed to operate under the same conditions. However, a spiral-grooved liner was incorporated in the inside vessel walls as shown in Figure 1. A coolant flow is maintained through the grooves of the liner during the operation of the units. This liner serves to keep the outer body cool.

One of the new units used to bond the 2 by 2 by 20 -in. assemblies has the same internal dimensions and end closures as the original cold-wall autoclave. The other unit is larger, possessing an inside diameter of $14 \mathrm{in.}$ with an inside depth of $72 \mathrm{in.}$, and will accommodate assemblies 3 by 3 by 36 in. A full Bridgman(2) closure was employed in both the top and bottom heads of this larger unit; however, a secondary head with a simple O-ring gasket closure is contained within the top head. This secondary head enhances quick and simple loading of the autoclave.

The achievement of a uniform heat zone over a long specimen length was difficult to achieve because of convection heat transfer. In efforts to improve heat distribution, several different sizes and types of internal resistance heaters were incorporated in the center of the autoclave. The most satisfactory heater employed during this investigation consisted of a muffle made up of twelve semicylindrical refractory units with embedded windings. Six of the units were aligned end to end to form one-half of the heater. Two heating elements are formed in each half and the grooves are filled with a high-purity alumina cement. These halves are assembled and wired together around a 16-gage stainless steel tube which is closed on one end. The heater is then placed into the autoclave and ceramic insulation is tightly packed around the assembled muffle unit. A 16-gage stainless steel tube, which closely fits inside this furnace liner, is used as a loading tube. The assembly contained in the sealed can is placed in the loading tube and the void space in the loading tube is filled with copper plates and sand. With this type furnace assembly, convection currents are greatly minimized.

The heater in the 14-in. -ID autoclave is $5 \mathrm{in}$. in diameter and is $54 \mathrm{in.}$ long. It has three individually controlled heating zones. A pressure-bonding cycle was made in this large unit at 10,000 psi for $4 \mathrm{hr}$ at $1500 \mathrm{~F}$ with only a 10 to $15 \mathrm{~F}$ variation over a. 36-in. zone.

Modification of the original thermocouple pressure-seal assembly permitted six thermocouples to be conveniently employed inside the autoclave. These thermocouples are placed at intervals along the length of the furnace and assembly to give a record and control of the temperature of the specimen and furnace. The readings of these thermocouples are recorded by the use of a Micromax recorder. The temperature plot for a typical pressure-bonding cycle is shown on the graph in Figure 2.

Helium gas is used for pressure bonding, although argon would be satisfactory. Helium, however, possesses a higher thermal conductivity than argon. (4) To obtain pressures of 10,000 psi, one of two available Andreas Hofer multistage horizontaldesign compressors is used. The maximum pressure of the smaller autoclave is reached in $45 \mathrm{~min}$. Approximately $90 \mathrm{~min}$ is required to reach pressure in the largest autoclave.

With the existing equipment, it is possible to bond numerous materials at elevated temperatures and pressures up to 10,000 psi. This equipment was developed to accommodate full cross-section as semblies with a maximum length of approximately 36 in. 


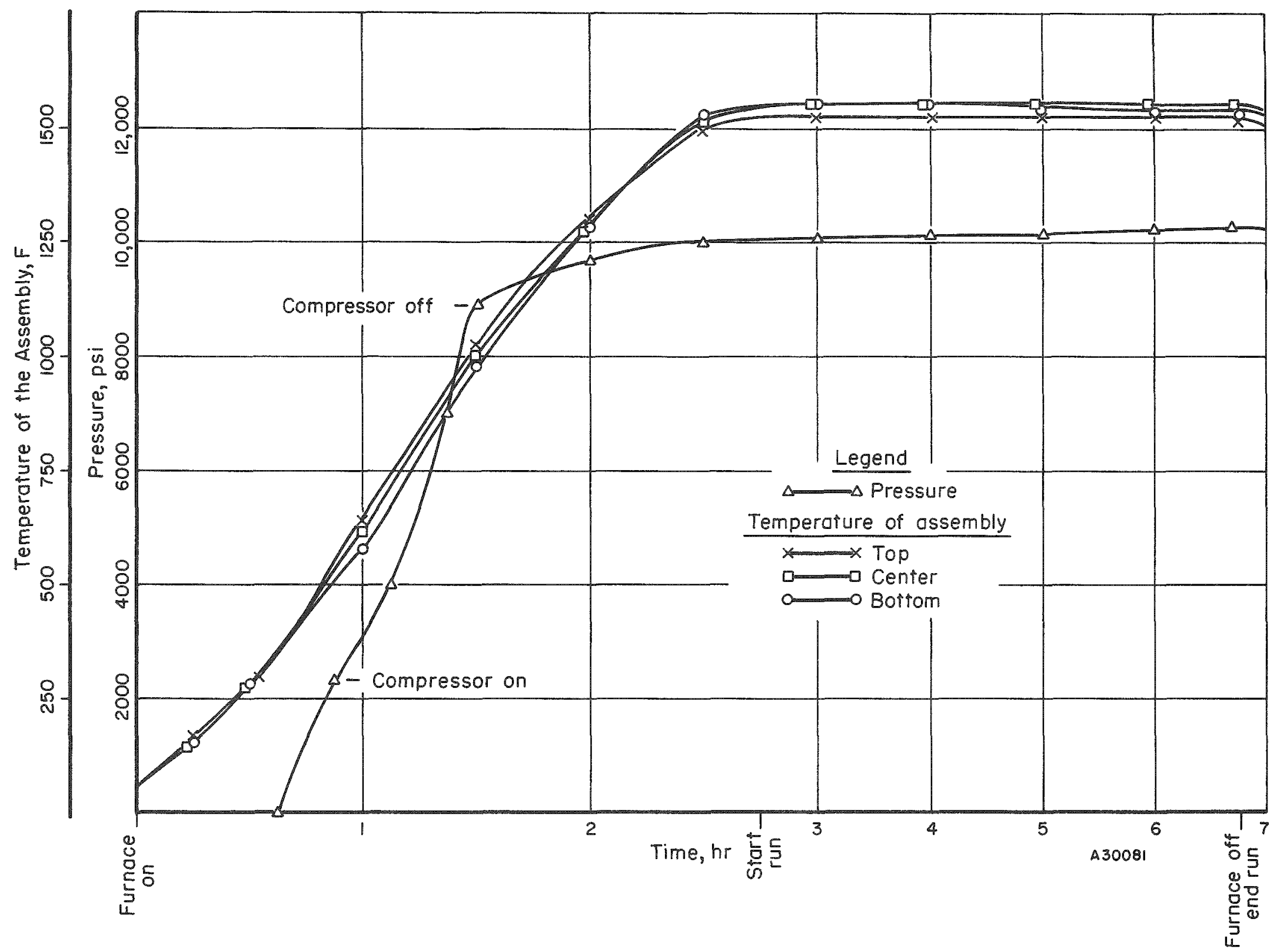

o.

FIGURE 2. A TYFICAL PRESSURE-BONDING CYCLE FOR A 2 BY 2 BY 20-IN. FLAT-PLATE ASSEMBLY 
Fabrication of Containers for: Pressure Bonding

The gas-pressure-bonding technique is dependent upon establishing a pressure differential between the inside of the sealed and evacuated container and the outside. In event of a leak in the container, there is no differential pressure; consequently, a container failure produces an unbonded set of components. The container must be fabricated of a thin material to allow the high external pressure to be transmitted uniformly through it to bring the components into intimate contact. The container must be low in cost, since it is discarded after each run.

During the feasibility study, it became apparent that the best results for this application were achieved using a stainless steel container of swastika design (Configuration $D$ in Figure 3).

Type 304 stainless steel sheet material and tubing were used for these containers. The side plates were fabricated from 0.018-in. thick sheet by shearing and forming a $90-$ deg flange 0.187 in. wide on one edge. The end plugs were fabricated from 0.080 -in. sheet. A form block fabricated slightly larger than the intended assembly size was machined of mild steel to very close dimensional tolerances.

All parts were degreased, assembled, and clamped into position on the form block preparatory to welding. For small assemblies, it was convenient to load the assembly in the end of the container; however, with the 2 by 2 by 6 -in. and 2 by 2 by 20-in. assemblies, end loading became impractical and side loading was employed. After Heliarc welding with one diffusion pass and one filler pass, the form block was removed from the edge-welded can. The assembly components were always preassembled into the container to assure proper fit. The components were then removed preparatory to cleaning for final assembly.

Fabrication of Components for Pressure Bonding

Since dimensional control over the gas-pressure-bonded assembly is governed by the dimensional tolerances of the individual components, care must be exercised in their fabrication.

During this study, all component thickness tolerances were held to \pm 0.0005 in., while all other tolerances were held to $\pm 0.001 \mathrm{in}$. with the exception of the three 2 by 2 by 20 -in. assemblies. The thickness tolerances were maintained in the same manner on the 2 by 2 by 20 -in. as semblies, but all other tolerances were relaxed to $\pm 0.002 \mathrm{in}$.

After the component materials had been rolled and surface conditioned to the correct thickness, they were sheared to approximate size, allowing a 0.030 in. finish stock on all edges. The components were then arranged in a fixture in sets of 10 to 15 and shaped or milled to size on all edges. Each component was separately inspected for size and finish. With an improved fixture design to accommodate and hold a greater number of components and with the application of gang machining practices, the cost of fabrication can be reduced considerably. It is also possible with relaxation of tolerances to shear or slit the components to the desired final size. 

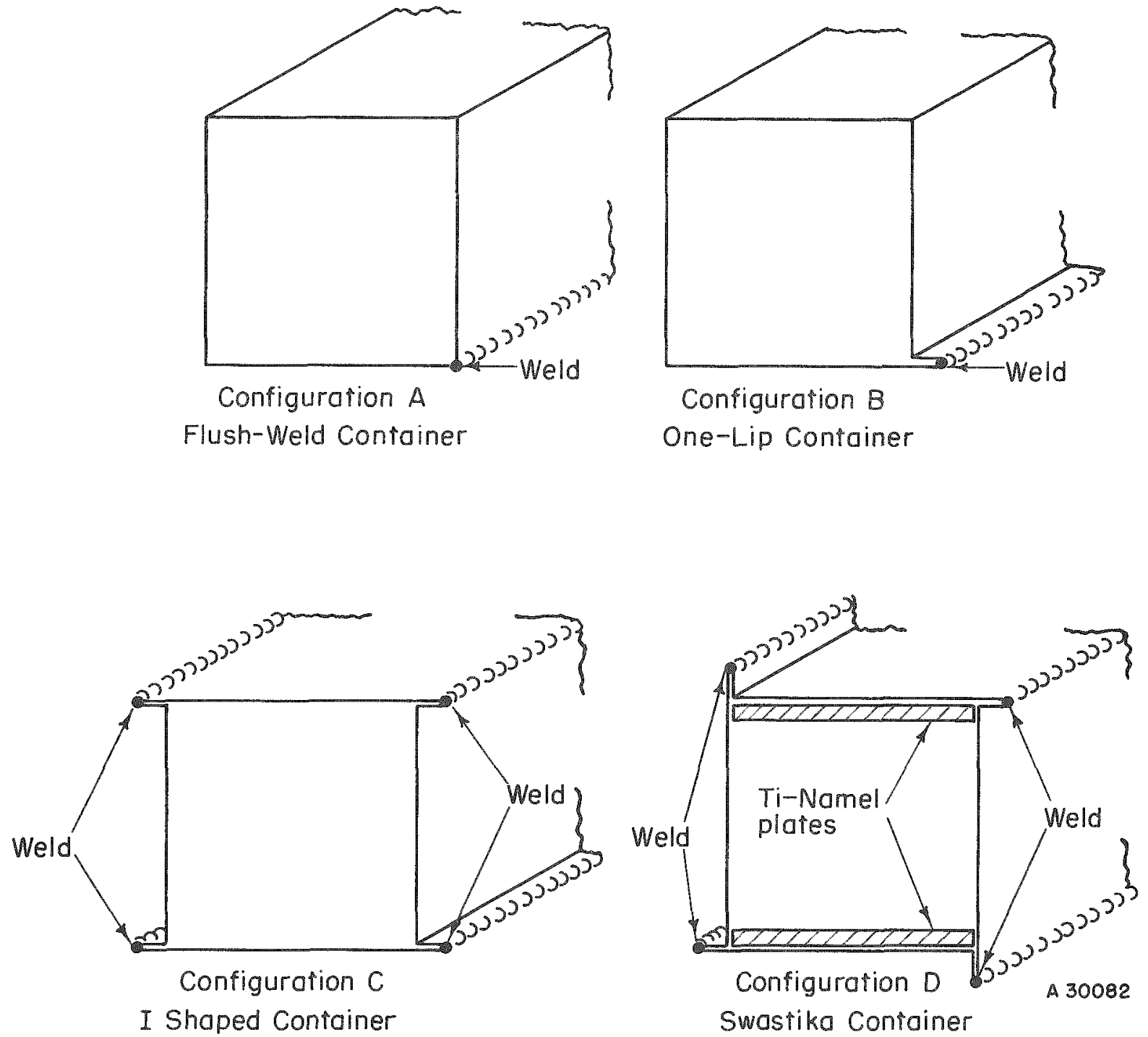

FIGURE 3. END VIEW OF THE VARIOUS SHAPED CONTAINERS STUDIED DURING THE FEASIBILITY INVESTIGATION 
During the feasibility study, Zircaloy -2 picture frames were machined to accommodate the cores, as shown in Figure 4. This was both a difficult and costly machining operation. Stamping of these frames was considered; however, after an examination of the fuel plates from pressure-bonded assemblies, it appeared that pieced-type frames could be used. The use of strips to form the frames saves on both machining and material cost.

An investigation into the feasibility of pieced-type frames was conducted using the configurations shown in Figure 5. The assembly of piece components for the bonding of a 6-in. -long assembly is shown in Figure 6. Two assemblies of each configuration were gas-pressure bonded at 10,000 psi for $4 \mathrm{hr}$ at $1550 \mathrm{~F}$. These six assemblies were sectioned and evaluated by microscopic examination.

Configuration III appeared to be the most satisfactory pieced frame design for the limited number of specimens bonded from the standpoint of loading ease and dimensional stability after bonding. All flat-plate fuel assemblies bonded during the later development stages of this program were bonded with Zircaloy-2 strip components.

\section{Cleaning Techniques}

After surface conditioning and machining the components to final size, they were carefully cleaned prior to final assembly for pressure bonding. All Zircaloy-2 and zirconium-uranium core alloy components, Ti-Namel spacer inserts and backup plates, and stainless steel cans were scrubbed with steel wool in alcohol and placed in a hot ethylene trichloride vapor bath for $15 \mathrm{~min}$. After degreasing, all components were washed in a cold Alconox solution, rinsed in cold running water, and subjected to a series of washings and rinses as outlined below:

(1) Scrubbed in a hot Alconox solution (180 F)

(2) Rinsed in cold running water

(3) Rinsed in hot water (180 F)

(4) Rinsed in cold running water

(5) Rinsed in hot water (200 F)

(6) Dried with paper towels.

Clean rubber gloves were worn during the cleaning, drying, and as sembling operations to prevent recontamination of the cleaned surfaces. The components for all assemblies were immediately assembled after cleaning, with the exception of the 2 by 2 by 20-in. assemblies. The components for these large assemblies were wrapped in metal foil and as sembled the following morning.

An investigation of ultrasonic cleaning to supplement the normal cleaning cycle was conducted as a portion of the surface-preparation study. The results of the study indicated that no appreciable improvement was obtained over the normal cleaning cycle. 

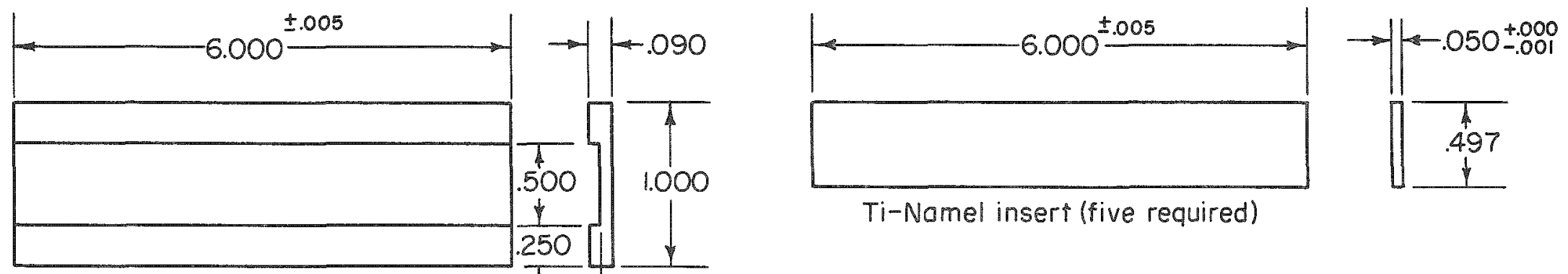

Ti-Nomel insert (five required)

Zircaloy-2 top cover (five required) $\uparrow \rightarrow+\neq .050+001$
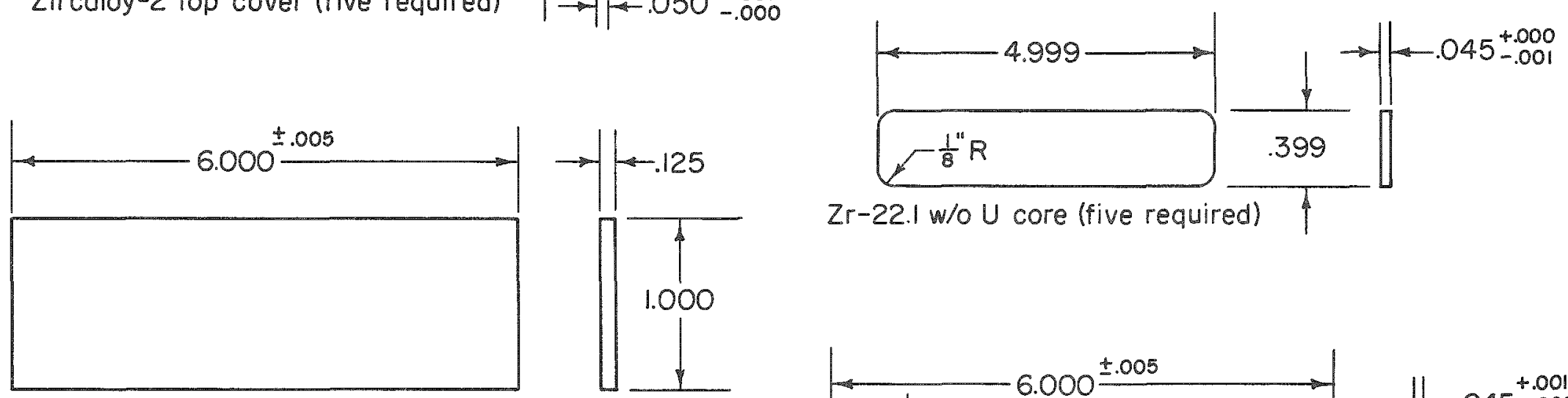

Zircoloy-2 dummy plate (one required)
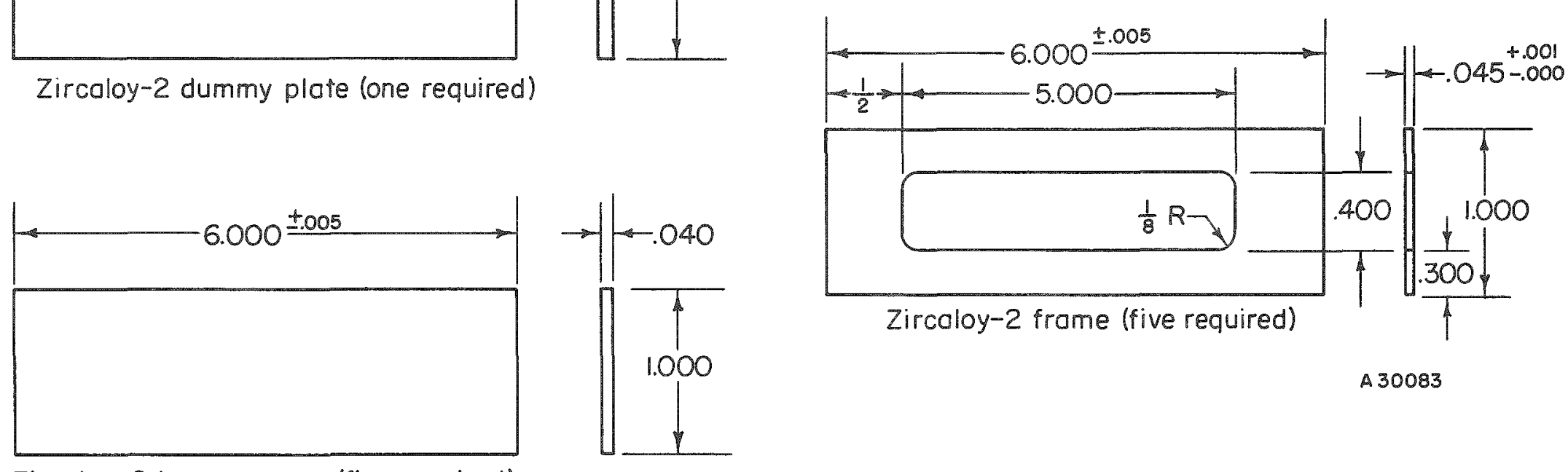

A 30083

Zircaloy -2 bottom cover (five required)

FIGURE 4. COMPONENTS FOR A 1 BY 1 BY 6-IN. SUBSCALE FLAT-PLATE ASSEMBLY Unless otherwise noted all dimensions $\pm .001 \mathrm{in.}$ 


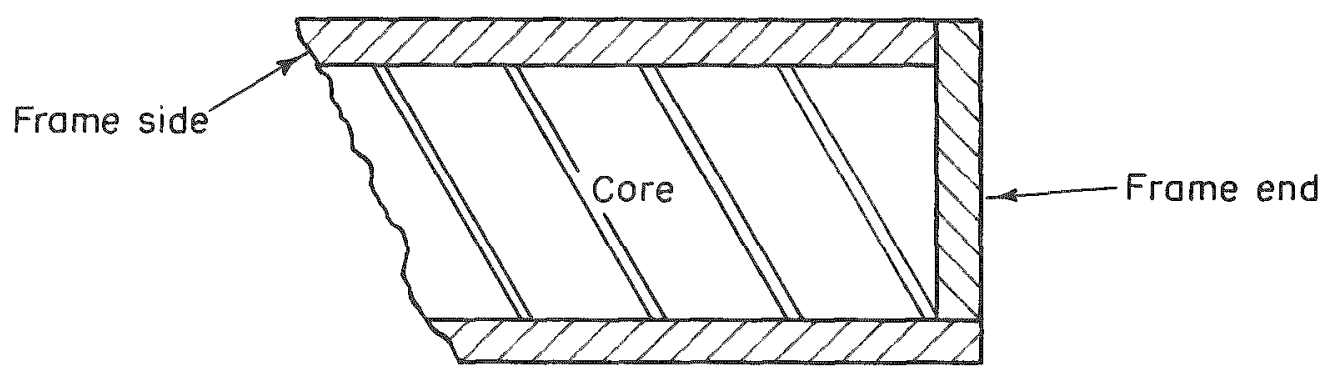

Configuration I
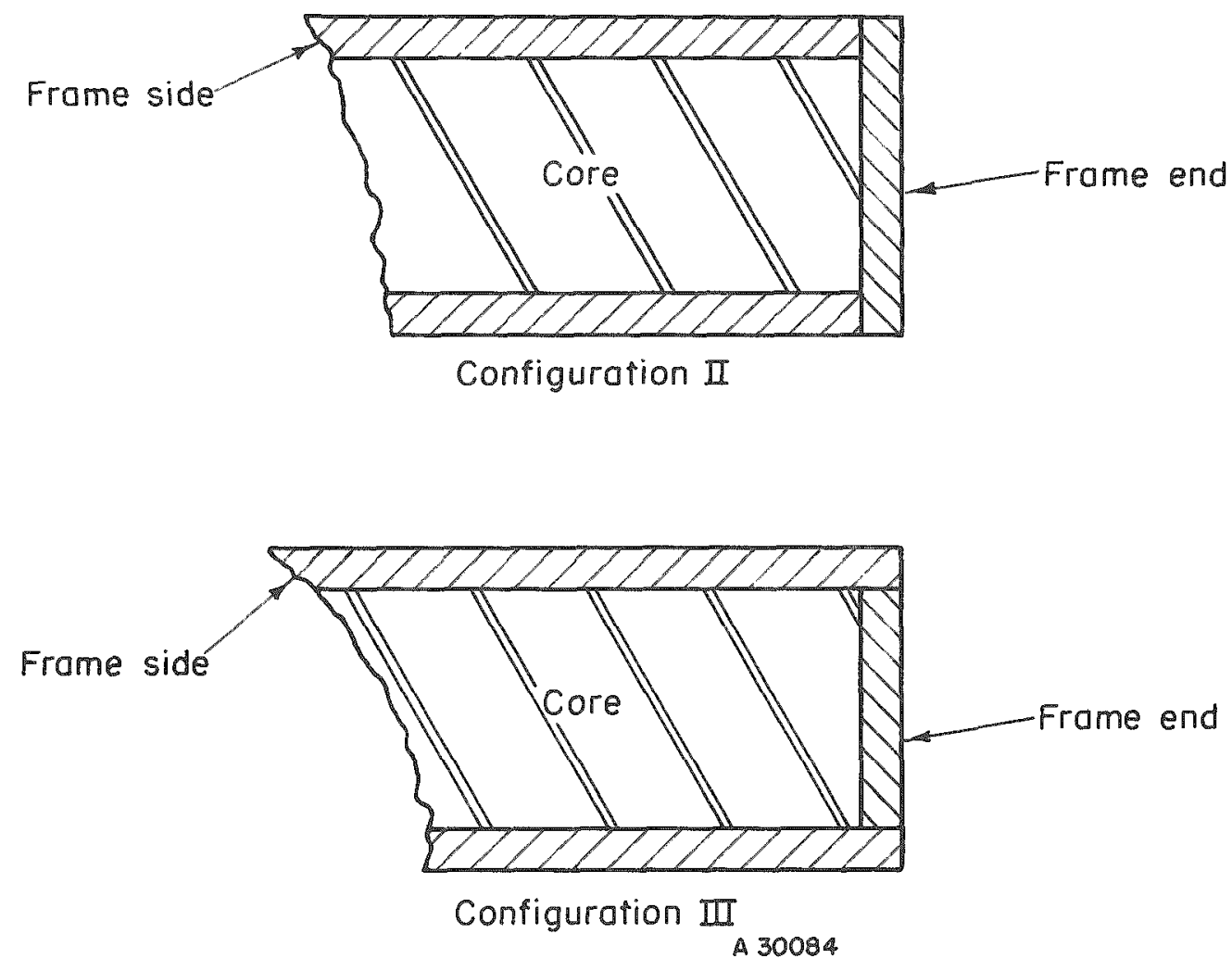

FIGURE 5. PIECED-FRAME DESIGN CONFIGURATIONS

Configuration III proved most satisfactory. 

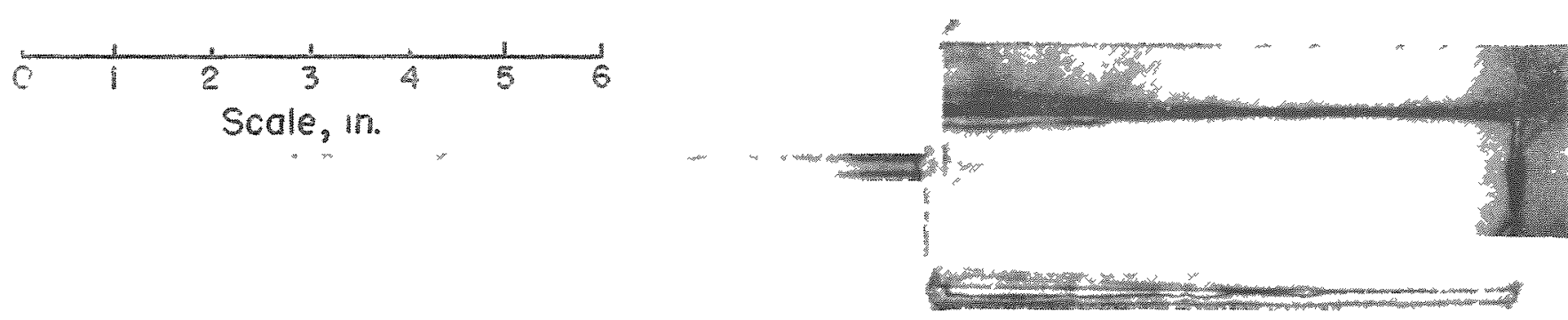

Stanless steel contaner
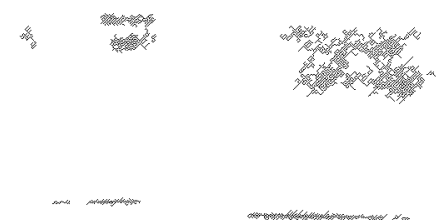

2 Ti-Namel top and bottom pressure plates

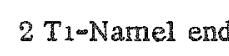
pressure plates

Container side plate

N45701
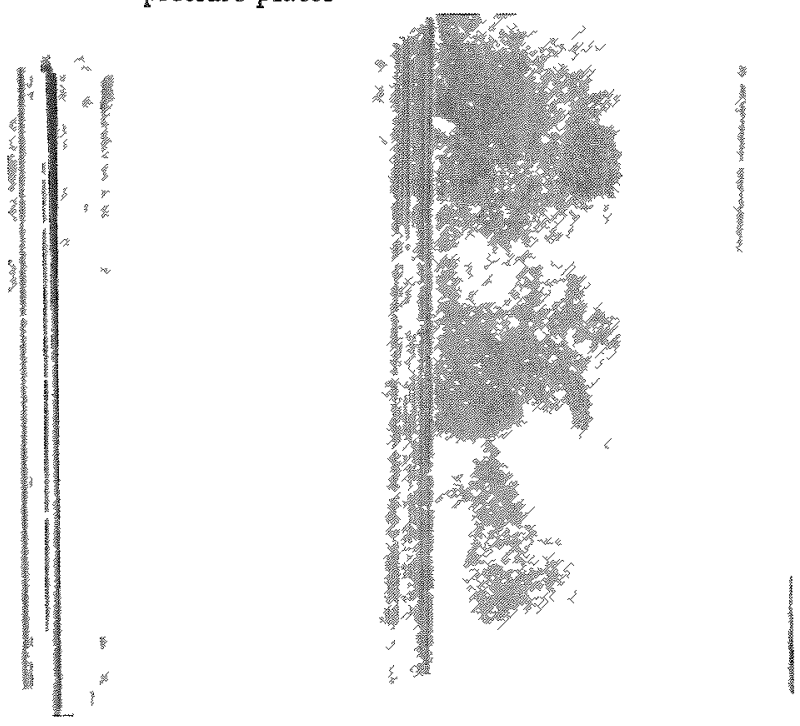

$32 \mathrm{Zr} \rightarrow \mathrm{C}^{\circ}$

covers

$16 \mathrm{Zn}-\mathrm{U}$

cores

\section{$15 \mathrm{Ti}-\mathrm{Name}$} channel inserts frame

sides
$32 \mathrm{Zr}-2$

frame ends

$\operatorname{Zr}-2=$ Zircaloy -2

FIGURE 6. ASSEMBLY OF COMPONENTS FOR THE PRESSURE BONDING OF A $6=1 \mathrm{~N}$. -LONG ASSEMBLY 
Assembly and Evacuation of Assemblies for Pressure Bonding

The components of the 2 by 2 by 6 -in. and 2 by 2 by 20 -in. assemblies were loaded into the stainless steel container from the side, as illustrated in Figures 7 and 8. The components for the feasibility study were loaded through the open end of the can prior to welding of the second end plug. The 0.080-in.-thick Ti-Namel pressure plates at the top, bottom, and ends of the as sembly were utilized to absorb the edge deformation of the can during bonding. These edge deformations, caused by the flow of metal into the flange areas of the container, form a slight lip along the Ti-Namel during deformation of the protective can.

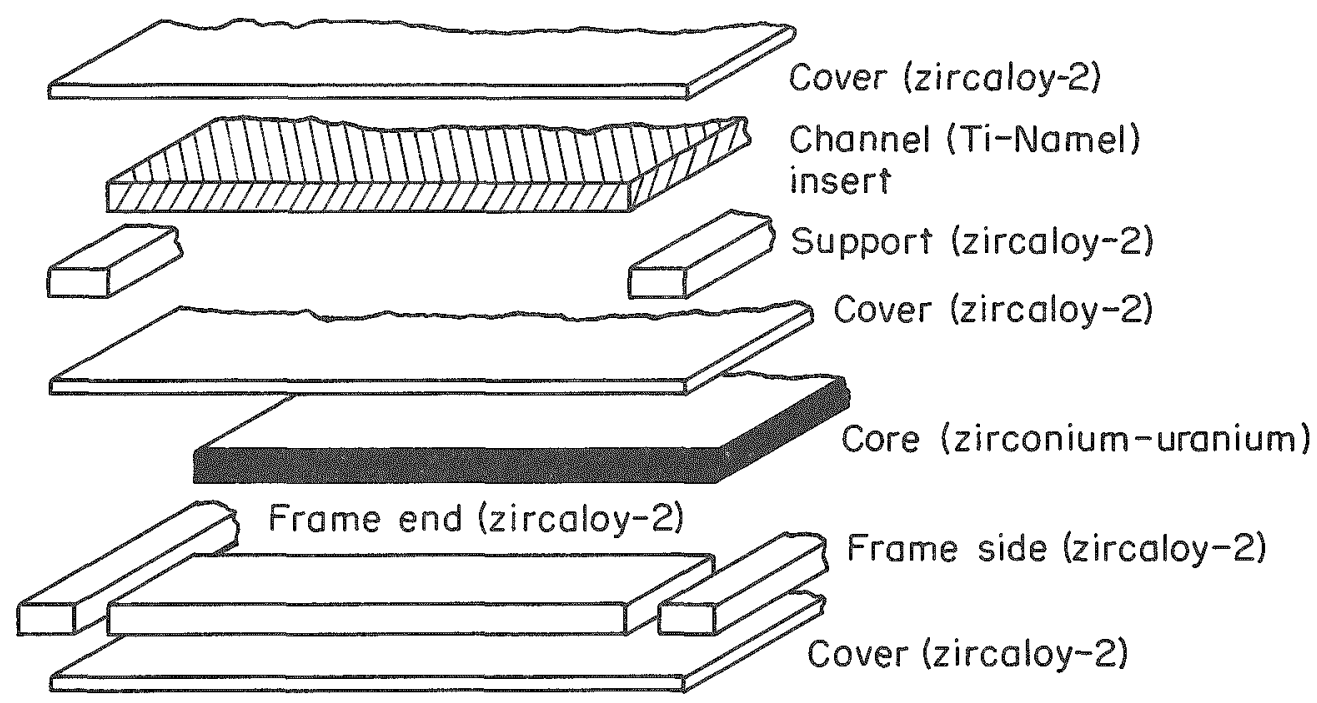

A 27439

\section{FIGURE 7. ASSEMBLY OF COMPONENTS FOR PRESSURE BONDING}

The time required for two men to assemble a 2 by 2 by $20-i n$. as sembly was between $1-1 / 2$ and $2 \mathrm{hr}$. This included assembly of the 157 components plus the 4 pressure plates and the clamping of the side container plate in place for welding.

Immediately after loading the assembly, the top plate of the container was Heliarc welded into place with one diffusion pass and one filler pass. Copper blocks were used next to the edges being welded to minimize heating of the assembly.

The welded containers were tested for leaks in the following manner: A highpressure hose was clamped to the evacuation tube and 50 to $75 \mathrm{psi}$ of helium pressure was applied to the inside of the container which was immersed in hot water. It should be noted that none of the 2 by 2 by 6 -in. or 2 by 2 by 20 -in. assemblies was lost during this study due to a container leak.

Provided no leaks were detected, the container was placed on a vacuum system. The container was evacuated to a pressure of $5 \times 10^{-3} \mathrm{~mm}$ of mercury, or less, prior to the sealing of the evacuation tube. 


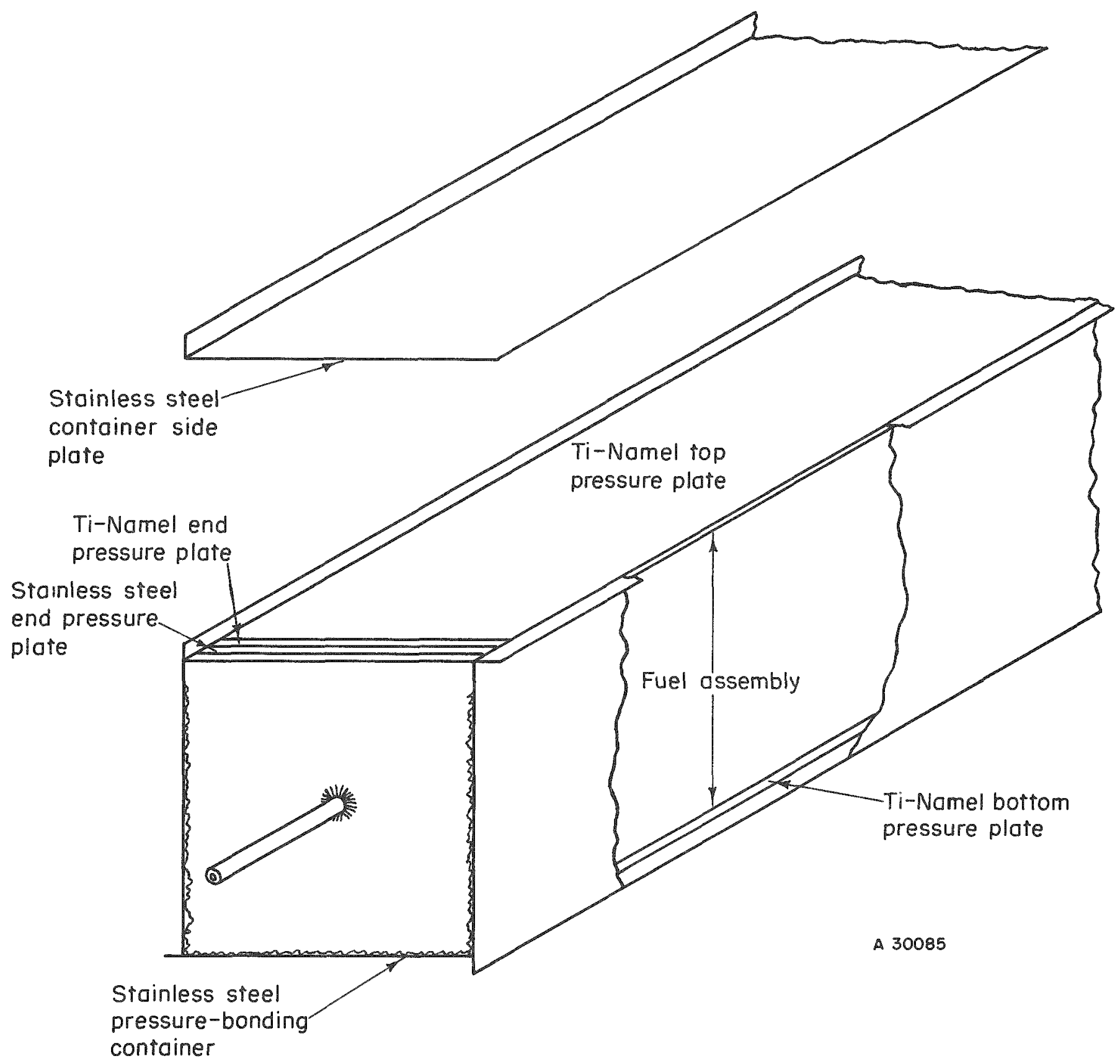

FIGURE 8. THE ASSEMBLAGE OF COMPONENTS PRIOR TO WELDING THE CONTAINER SIDE PLATE IN PLACE 


\section{GAS-PRESSURE-BONDING RESULTS}

Feasibility Study

Initially, a 6-month study was conducted by Battelle for Bettis to determine the feasibility of adapting the pressure-bonding process to the production bonding of Zircaloy-2-clad zirconium-uranium flat-plate as semblies. Encouraging results were achieved during this investigation. Excellent channel spacing, over-all dimensional control, and bond integrity were obtained.

In conducting these tests, subscale assemblies measuring 1 by 1 by 3 in. and 1 by 1 by 6 in. with five fuel plates, one dummy plate, and five channel spacers were used, as shown in Figure 4. These subscale assemblies contained machined Zircaloy-2 frames and covers, uranium-zirconium cores, and Ti-Namel channel inserts.

The initial container used for these test assemblies was the flush-weld container, Configuration A, as shown in Figure 3. This container was difficult to form and loading of the assembly was troublesome due to the bend radius at the corners and the restriction of the welds. Assemblies bonded in this type container were deformed on the side edges due to the wrinkling of the container.

Investigations into the use of various shaped containers, as illustrated in Figure 3, and materials for the se containers were conducted to endeavor to find one type containe $r$ that could be easily loaded and maintain assembly tolerances without deformation.

The use of the one-lip container did away with the weld restriction; however, loading was still difficult due to the bend radius on the other three corners. The assemblies were also deformed by wrinkling at the corners of the container.

The I-type container (Configuration C) allowed movement of the side flanges to take up any wrinkling; however, small lips were formed on the assembly edges where they were forced into the container flanges. It was also difficult to maintain parallel flanges during the forming of this container.

The swastika container was easily sheared, formed, and welded. The side flanges allowed movement at the corners of the container to prevent wrinkling. Thin Ti-Namel plates, 0.050 to $0.080 \mathrm{in}$. thick, were placed inside the container at the top and bottom of the assembly to allow for flow along the flanges of the container. Assemblies bonded in the swastika-type container appeared to be well formed with no deformation at the edges.

The stainless steel container appeared to retain enough rigidity, while coming up to pressure and temperature, to keep the assembly aligned and restrict flow in between the components which would cause them to hang up along the sides of the container. However, at pressure and temperature the stainless steel container allowed uniform pressure to be transmitted to the assembly. Although containers of copper and Ti-Namel produced promising results, it was apparent from these investigations that stainless steel containers of the swastika design gave the best results for this type application. 
To control distortion and channel spacing, several methods of jigging were investigated during the feasibility study for small-scale specimens. The most promising of these jigging methods investigated consisted of using two end blocks of Ti-Namel $1 / 2$ in. thick machined to the dimensions of the test assembly. The center portions of these end blocks were machined out to key in the Ti-Namel spacers that were made to extend $0.5 \mathrm{in}$. beyond the ends of the assembly. Ti-Namel pressure plates $0.250 \mathrm{in}$. thick were placed on the top and bottom of the test assembly and end blocks. The subscale assembly using this technique of jigging exhibited excellent channel spacing, with no shifting of the plates. The average local channel tolerance allowable was \pm 0.009 in. and the variation obtained was -0.0017 to +0.0020 in., while the average channel tolerance allowable for the whole subscale assembly was $\pm 0.005 \mathrm{in}$. and the variation obtained was +0.0005 in. It appeared that with suitable containers jigging would be unnecessary.

Figure 9 illustrates the preassembly of a single flat-plate as sembly used in the feasibility study to determine the dimensional control that might be expected during bonding of larger specimens. After pressure bonding, the stainless steel containers were stripped. This was accomplished by sawing off the container end near the Ti-Namel end pressure plate to prevent damage of the assembly. The four flanges were then removed, and the thin stainless steel side plates were easily stripped from the assembly. After stripping the container from the assembly, the extra Ti-Namel pressure plates were easily removed. The flat-plate as semblies were then subjected to a pickling treatment to dissolve the Ti-Namel spacers.

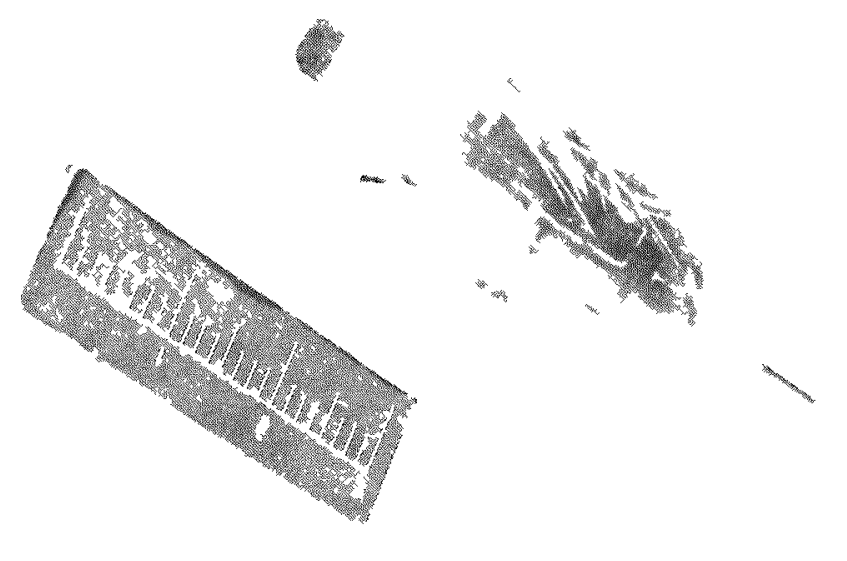

$\mathrm{N} 49184$

FIGURE 9. SINGLE FLAT-PLATE ASSEMBLY PREASSEMBLED INTO A SWASTIKA-TYPE CONT AINER

Those flat-plate assemblies having plain Ti-Namel channel inserts were treated in a 50-50 water-nitric acid solution at $180 \mathrm{~F}$ with a $0.5 \mathrm{w} / 0$ urea addition to the total solution. The urea addition increased the reaction rate between the acid solution and the Ti-Namel, and prevented the pickled surfaces from becoming passive to the acid 
solution. In the later phase of the study, chromium-plated Ti-Namel channel inserts were utilized and an additional pickle was required to remove the chromium from the channels. This consisted of a second treatment in a 33 volume per cent hydrochloric acid-water solution. It required 55 to $60 \mathrm{hr}$ to dissolve the 15 chromium-plated Ti-Namel channel spacer inserts from the 2 by 2 by 20 -in. assembly.

Preliminary evaluation of all pressure-bonded plates and assemblies was made on the basis of 3 -day $680 \mathrm{~F}$ water or $750 \mathrm{~F}$ steam corrosion test, metallographic examination, optical-comparator measurements, and mechanical bend tests.

The entire subscale subassembly was corrosion tested to determine if the corrosion properties of the Zircaloy -2 had been altered during pressure bonding and to determine if the corrosion resistance of the bond interfaces was satisfactory. Oneinch-square coupons were sectioned from the center of the surface-preparation study specimens for corrosion testing. The results from this corrosion study were correlated with the surface-preparation program to determine the effects of surface preparation on the corrosion resistance of the Zircaloy-to-Zircaloy bond interfaces. The corrosion resistance of the Zircaloy- 2 face adjacent to the Ti-Namel during bonding was examined for evidences of diffusion during the bonding cycle.

Longitudinal and transverse sections of both the bonded surface-preparation study plates and the bonded assemblies were metallographically inspected to determine bond quality, uniformity, and continuity.

The bonds produced were uniform and comparable in strength to bonds produced by other cladding techniques. Figure 10 shows a typical Zircaloy-to-Zircaloy bond and a Zircaloy-to-zirconium-22 w/o uranium bond using machine-shaped surfaces. These results indicated that the gas pressure-bonding process was a feasible method of producing integral flat-plate assemblies.

The mechanical bend test was conducted in a fixture which bent a single plate section from the assemblies with uniform pressure through a 90-deg arc. None of the plates failed by bond rupture except those prepared by pressure bonding of improperly prepared Zircaloy-2 surfaces. All failures were transverse to the bond interface.

\section{Surface-Preparation Investigation}

During the feasibility study, all components were fabricated from hot-rolled matexial with all surfaces being machine-shaped to size. Excellent bonds were produced during pressure bonding, as illustrated by the complete grain growth across the interface of the Zircaloy-2 components and the Zircaloy-to-core components in Figure 10. However, this method of surface preparation is time consuming, is expensive, and involves losses in material that would not be encountered with other surface-preparation processes. One of the primary aims of the development program was to determine an inexpensive surface-preparation method that would yield consistently strong and corrosion-resistant metallurgical bonds during cladding of Zircaloy-to-Zircaloy components. 


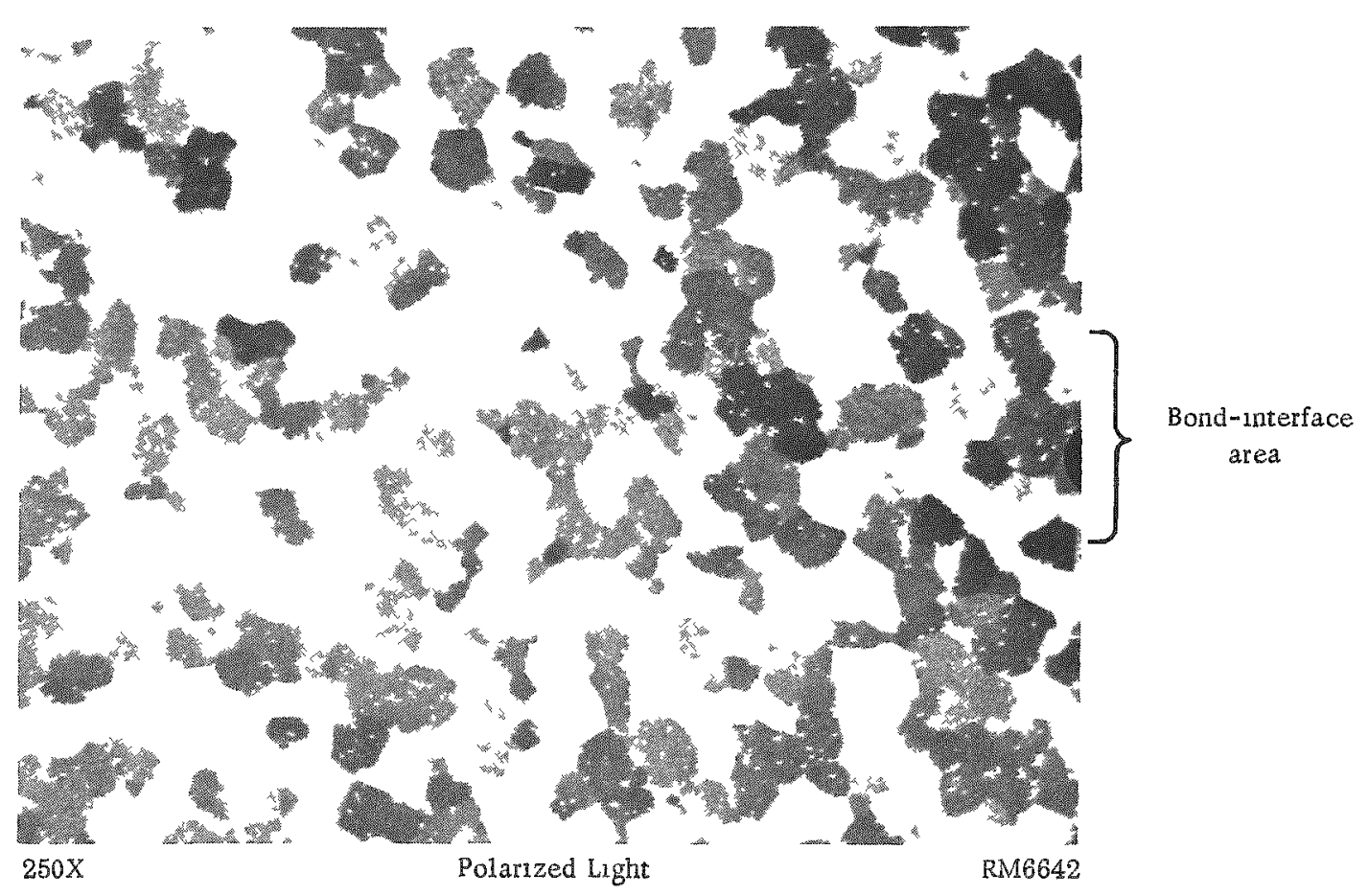

a. Zircaloy-to-Zircaloy Bond

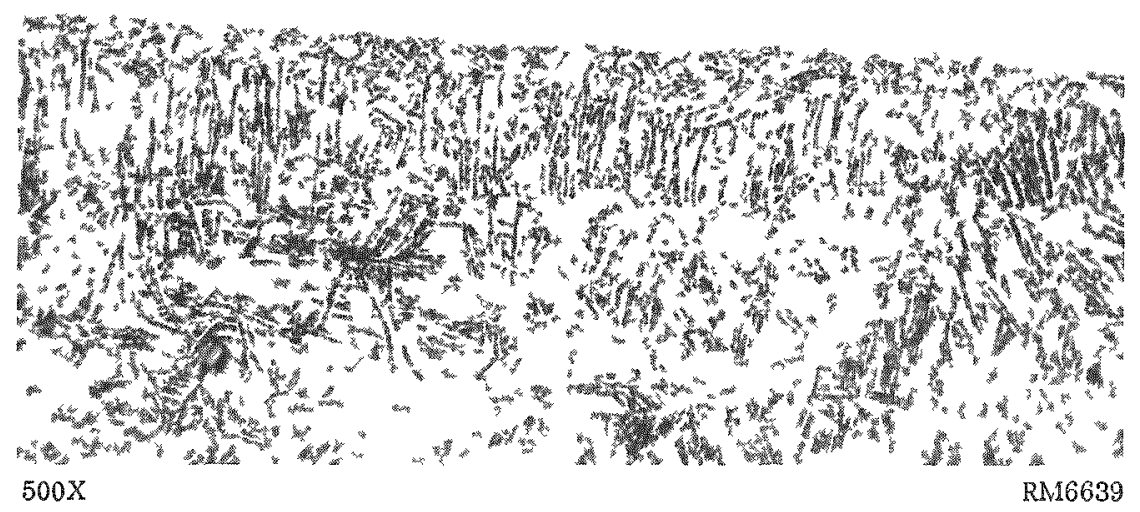

b. Zircaloy-to-Zirconum-22 w/o Uranum Bond

FIGURE 10. BOND INTERFACES OBTAINED WIT'H BONDING SURFACES PREPARED BY MACHINING Assemblues were gas pressure bonded at 10,000 psi for $4-1 / 2$ hr at $1550 \mathrm{~F}$. 
During the pressure-bonding operation, only a minimum amount of deformation is required to fill void spaces and for ce the components into intimate contact; consequently, there is little opportunity to break down surface films during bonding. Therefore, the method of surface preparation utilized greatly affects the quality of the resultant bond.

Specimen containers that would embody five or six surface-preparation specimens were employed to obtain the greatest amount of information for the least number of pressure-bonding cycles. Hot-rolled and machine-ground Ti-Namel was used between the Zircaloy-2 specimens to facilitate their separation after bonding. All assemblies were pressure bonded for approximately $4 \mathrm{hr}$ at a temperature of $1550 \mathrm{~F}$ and a pressure of 10,000 psi.

An atmosphere-melted hot-rolled Zircaloy-2 plate specimen from which 0.015 in. of surface metal had been shaped from each of the bonding surfaces was bonded and used as a reference specimen. The desired bond was one in which the re was complete grain growth across the interface with no trace of contamination or voids, as shown in Figure 11.

Atmosphere-melted Zircaloy-2 was utilized in the initial phases of the development study; however, during the later phase vacuum-melted Zircaloy-2 was also used because of its more consistent corrosion resistance. The atmosphere-melted Zircaloy-2 material was prepared by hot rolling 0.125 -in. -thick plate at $1550 \mathrm{C}$ down to approximately $0.050 \mathrm{in.}$ The resultant material was grit blasted and pickled. Two pickling treatments were employed. They consisted of a 45 nitric acid-50 water5 hydrofluoric acid solution or a 50 nitric-50 water, with an addition of $5 \mathrm{~g}$ of ammonium bifluoride per liter of solution. The former solution was used at a bath temperature of $140 \mathrm{~F}$ and the latter solution was employed at room temperature. The pickled stock was carefully rinsed in water and further reduced cold to $0.030 \mathrm{in}$. This material served as a base for all surface-preparation studies for all of the specimens prepared from atmosphere-melted Zircaloy-2.

The vacuum-melted material was taken from cold rolled 1 -in. -thick plate supplied by Bettis. This material was warm rolled at $1150 \mathrm{~F}$ to a 0.038 -in. thickness and vapor blasted prior to sectioning for subsequent surface-preparation studies.

Evaluation of Machined Surfaces

The removal of a small amount of surface metal by shaping or milling either hotor cold-rolled Zircaloy-2 surfaces appears to produce excellent bond properties, as illustrated in Table 1. Moderate controls are required during machining of the Zircaloy-2 surfaces to prevent the formation of an oxide surface layer due to overheating of the Zircaloy-2. Evaluation of the corrosion and metallographic data for machined specimens contained in Table $\mathbb{I}$ indicates that without sufficient control during machining the subsequent bonded specimen contains spots exhibiting corrosion and absence of grain growth. All of the specimens discussed in the table tested well in $90-$ deg bend tests with no evidence of rupture or parting at the original inter face. Although excellent results were obtained with machined surfaces, this method of sur face preparation did not appear to be attractive because of the high relative costs compared with other methods. 


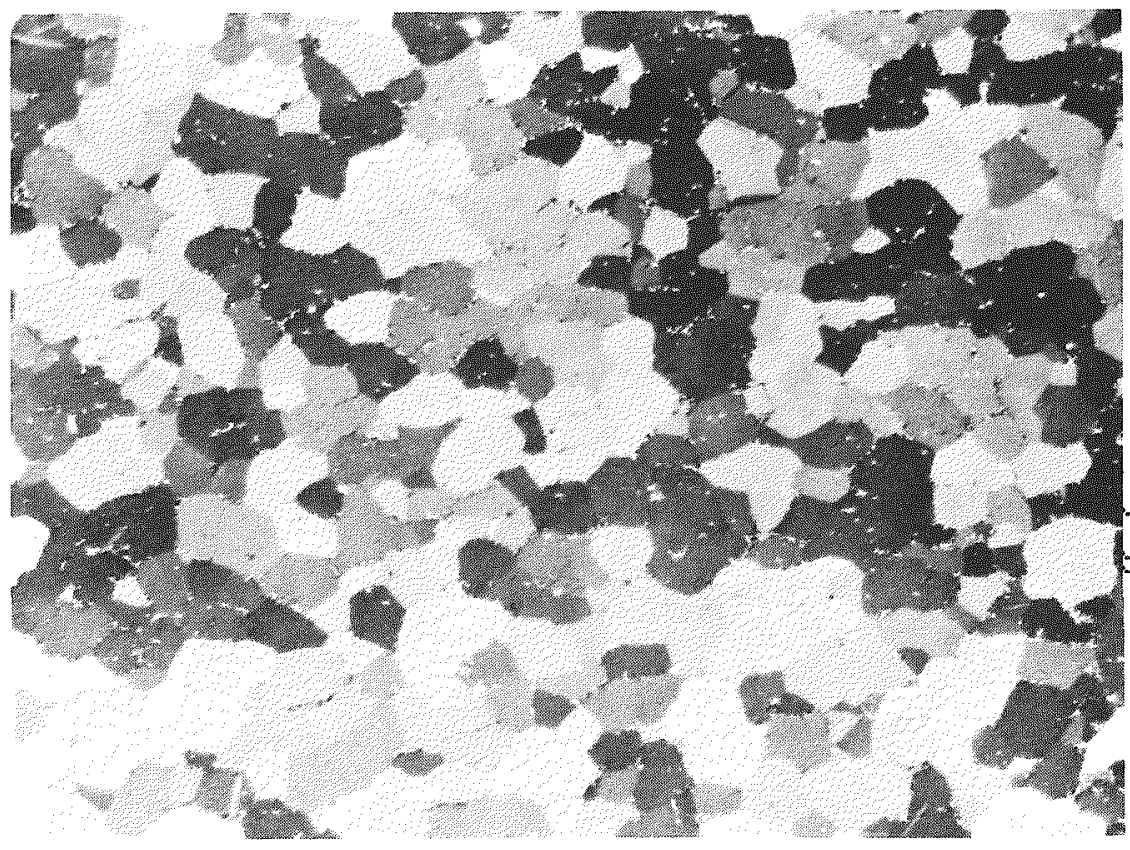

$250 x$

Polarized Light

a. As Bonded

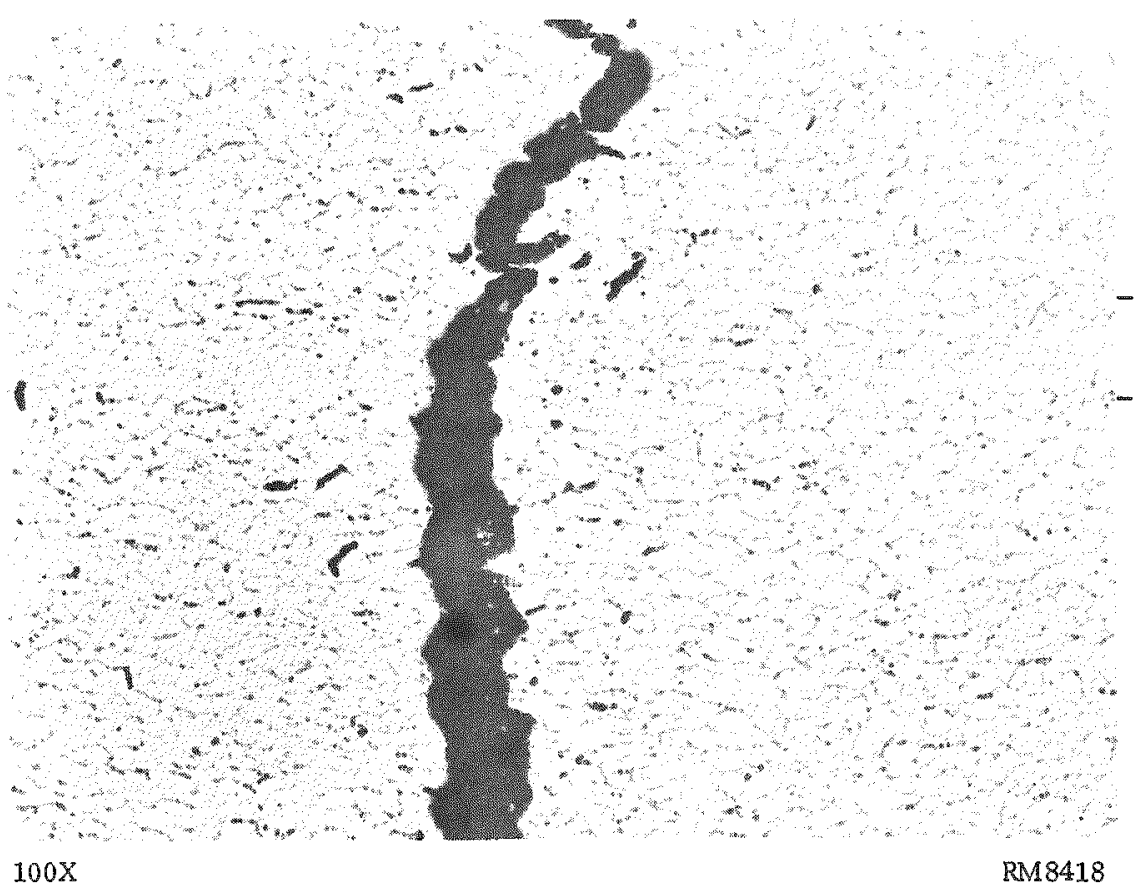

Area of bond

interface

Area of bond interface

b. After Bend Testing

FIGURE 11. BOND INTERFACE OBTAINED ON ZIRCALOY -TO-ZIRCALOX SPECIMENS WITH MACHINED SURFACES

$0.015 \mathrm{in}$. of surface metal was shaped from the bonding surfaces of the atmospheremelted hot-rolled Zircaloy-2 prior to pressure bonding at $1550 \mathrm{~F}$ for 4 hr at 10,000 psi. 
TABLE 1. EVALUATION OF ZIRCALOY-2 SPECIMENS BONDED WITH MACHINED SURFACES

\begin{tabular}{|c|c|c|c|c|c|}
\hline \multirow[b]{2}{*}{$\begin{array}{c}\text { Zircaloy - } 2 \text { Fabrication } \\
\text { History }\end{array}$} & \multicolumn{2}{|c|}{ Surface Treatment } & \multicolumn{2}{|c|}{ Metallographic Evaluation } & \multirow[b]{2}{*}{$\begin{array}{l}\text { Corrosion-Test Results } \\
\text { (30 Days in } 750 \mathrm{~F} \text { Steam) }\end{array}$} \\
\hline & $\begin{array}{c}\text { Metal } \\
\text { Removed, in. }\end{array}$ & Method & Contamination & $\begin{array}{c}\text { Grain Growth, } \\
\text { per cent }\end{array}$ & \\
\hline $\begin{array}{l}\text { Vacuum melted, } \\
\text { rolled at } 1150 \mathrm{~F}\end{array}$ & 0.003 & Shaping & None apparent & 100 & No attack \\
\hline $\begin{array}{l}\text { Vacuum melted, } \\
\text { cold rolled }\end{array}$ & 0.003 & Shaping & None apparent & 100 & No attack \\
\hline $\begin{array}{l}\text { Atmosphere melted, } \\
\text { hot rolled at } 1550 \mathrm{~F}\end{array}$ & 0.015 & Shaping & None apparent & 100 & No attack \\
\hline
\end{tabular}


Evaluation of As-Rolled Surfaces

From the standpoint of economy, the most desirable surface for bonding would be one which makes use of the as-rolled surface and does not require any metal removal during cleaning prior to bonding. Attempts were made to use as-rolled surfaces by either washing cold-rolled material that had no apparent surface scale or by vapor blasting and washing hot-rolled material. Difficulty was encountered with the presence of oxide or other contamination on both of these surfaces. It was not possible to obtain a satisfactory bond without subjecting the as-rolled surfaces to an additional machining or abrading treatment. Considerable amounts of oxide were present on the surfaces of the hot-rolled stock even after vapor blasting. The cold-rolled stock also had a significant amount of residual contamination after the wash cycle. Apparently the bulk of this oxide does not diffuse away from the interface during pressure bonding; consequently, some of the contamination is observed at the interface after bonding. The results of a number of bonding trials on the as-rolled specimens are tabulated in Table 2, with typical bonds illustrated in Figure 12. None of the results obtained with as-rolled surfaces, as indicated in the table, were sufficiently encouraging to prompt any additional study on this type of surface preparation. The results of the evaluation of bonding as-rolled specimens can be summarized as follows:

(1) A maximum of 5 per cent grain growth was obtained.

(2) Metallographic observations always revealed contamination along the bond interface.

(3) The specimens tested poorly in bend tests.

(4) Corrosion results obtained along the bond interface were erratic.

\section{Evaluation of Pickled Surfaces}

Pickling is an economical method of removing surface scale and was investigated as a method of surface preparation for Zircaloy-2. A surface film which interfered with the bonding process was formed on the Zircaloy surfaces during pickling with either a nitric-hydrofluoric acid solution or with a bifluoride solution. Bonds obtained with pickled surfaces were not acceptable for this program, as it was felt that the lack of grain growth along the interface was a potential plane of weakness. A typical bond formed with pickled surfaces is illustrated in Figure 13. Table 3 summarizes the results obtained with bonding of pickled surfaces. The lack of grain growth and the inconsistent corrosion results are reported in the table. 
TABLE 2. EVALUATION OF ZIRCALOY-2 SPECIMENS BONDED WITH AS-ROLIED MATERIAL

\begin{tabular}{|c|c|c|c|c|}
\hline \multirow[b]{2}{*}{$\begin{array}{c}\text { Zircaloy }-2 \text { Fabrication } \\
\text { History }\end{array}$} & \multirow[b]{2}{*}{ Surface Treatment } & \multicolumn{2}{|c|}{ Metallographic Evaluation } & \multirow[b]{2}{*}{$\begin{array}{l}\text { Corrosion-Test Results } \\
\text { (3 Days in } 750 \text { F Steam) }\end{array}$} \\
\hline & & Contamination & $\begin{array}{l}\text { Grain } \\
\text { Growth, } \\
\text { per cent }\end{array}$ & \\
\hline \multirow[t]{3}{*}{$\begin{array}{l}\text { Atmos phere melted, } \\
\text { cold rolled }\end{array}$} & None & Continuous & 5 & $\begin{array}{l}\text { Intermittent oxide along } \\
\text { the bond interface }\end{array}$ \\
\hline & Vapor blasted with $\mathrm{Al}_{2} \mathrm{O}_{3}$ & Continuous, heavy & 0 & $\begin{array}{l}\text { Continuous oxide layer } \\
\text { along the interface }\end{array}$ \\
\hline & $\begin{array}{l}\text { Vapor blasted with zirconium } \\
\text { oxide }\end{array}$ & Continuous, heavy & 0 & $\begin{array}{l}\text { No corrosion was observed } \\
\text { along the interface }\end{array}$ \\
\hline $\begin{array}{l}\text { Vacuum melted, } \\
\text { rolled at } 1150 \mathrm{~F}\end{array}$ & None & $\begin{array}{l}\text { Specimen failed along } \\
\text { the bond }\end{array}$ & & Not tested \\
\hline $\begin{array}{l}\text { Atmosphere melted, } \\
\text { cold rolled } 15 \text { per cent }\end{array}$ & None & Slight & 0 & $\begin{array}{l}\text { Intermittent oxide layers } \\
\text { along the interfaces }\end{array}$ \\
\hline
\end{tabular}




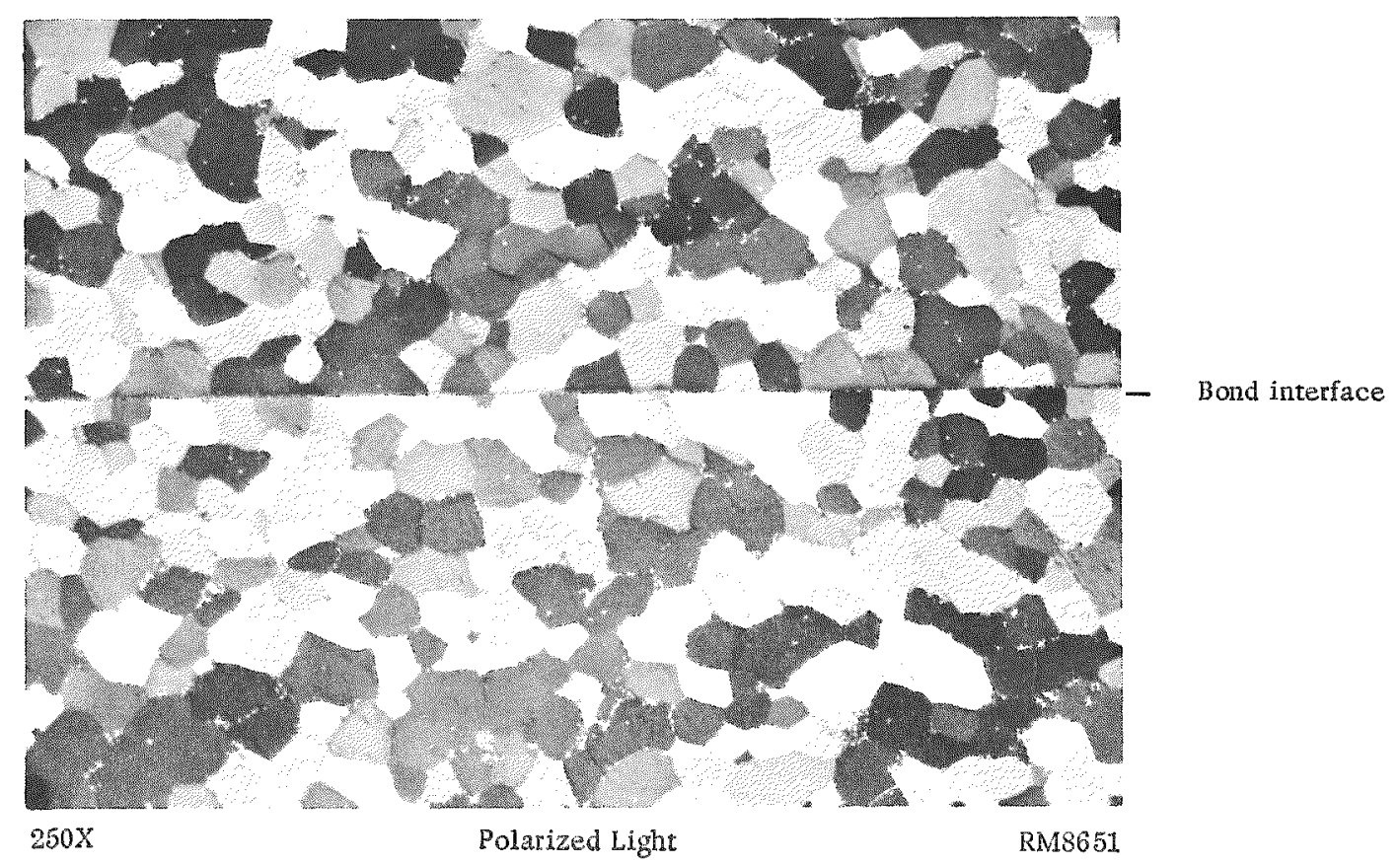

a. Cold-Rolled Stock Vacum Annealed for $1 \mathrm{hr}$ at $1550 \mathrm{~F}$

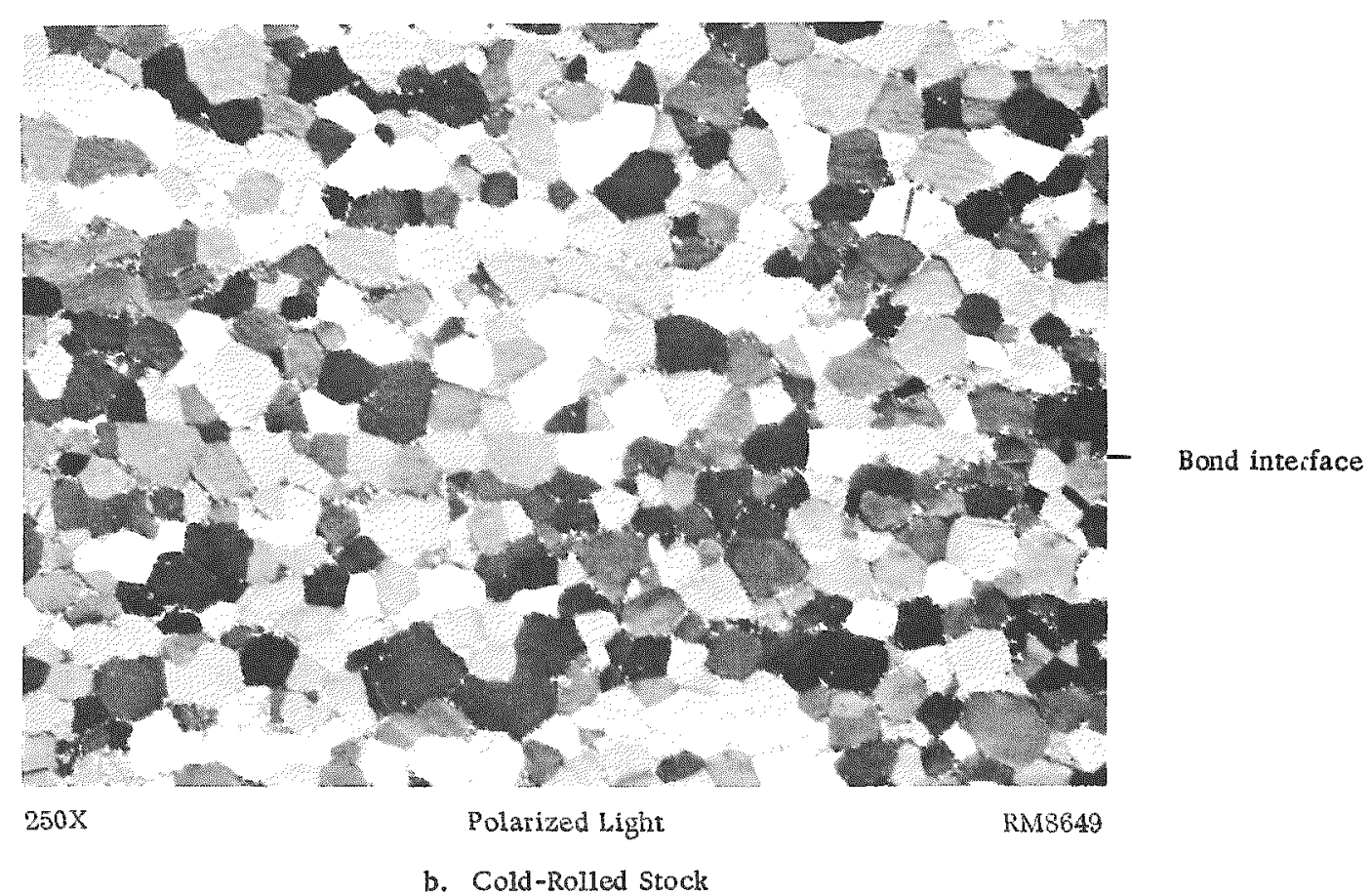

FIGURE 12. TYPICAL INTERFACES OF ZIRCALOY-TO-ZIRCALOY SPECIMENS BONDED AS-ROLLED WITH ONLY WASHING USED FOR SURFACE PREPARATION

Gas-pressure bonded at $1550 \mathrm{~F}$ for 4 hr at 10,000 psi. 
TABLE 3. EVALUATION OF BONDS OBTAINED WITH PICKLED ZIRCALOY - 2 SURFACES

\begin{tabular}{|c|c|c|c|c|c|}
\hline \multirow{2}{*}{$\begin{array}{c}\text { Zircaloy }-2 \\
\text { Fabrication History }\end{array}$} & \multicolumn{2}{|c|}{ Surface Treatment } & \multirow{2}{*}{\multicolumn{2}{|c|}{ Metallographic Evaluation }} & \multirow{2}{*}{$\begin{array}{l}\text { Corrosion-Test Results } \\
\text { (3 Days in } 750 \text { F Steam) }\end{array}$} \\
\hline & $\begin{array}{c}\text { Metal } \\
\text { Removed, } \\
\text { in. }\end{array}$ & $\begin{array}{l}\text { Pickling } \\
\text { Solution } \\
\end{array}$ & & & \\
\hline \multirow[t]{5}{*}{$\begin{array}{l}\text { Atmosphere melted, } \\
\text { cold rolled }\end{array}$} & 0.002 & Bifluoride(a) & Insignificant & 0 & $\begin{array}{l}\text { Spots of oxide along the } \\
\text { interface }\end{array}$ \\
\hline & 0.003 & Bifluoride (a) & Slight & 0 & $\begin{array}{l}\text { Intermittent oxide along } \\
\text { the interface }\end{array}$ \\
\hline & 0.004 & Bifluoride(a) & Insignificant & 0 & $\begin{array}{l}\text { Spots of oxide along the } \\
\text { interface }\end{array}$ \\
\hline & 0.001 & $H F(b)$ & Very faint & 0 & No attack \\
\hline & 0.002 & $H F^{(b)}$ & Very faint & 0 & No attack \\
\hline
\end{tabular}

(a) A 50 water-50 nitric acid solution to which was added $5 \mathrm{~g}$ per liter of ammonium bifluoride.

(b) A 45 per cent nitric-5 per cent hydrofluoric-50 volume per cent water solution in an ultrasonic bath.

(c) Same solution as in (b); however, no ultrasonic bath was employed. 


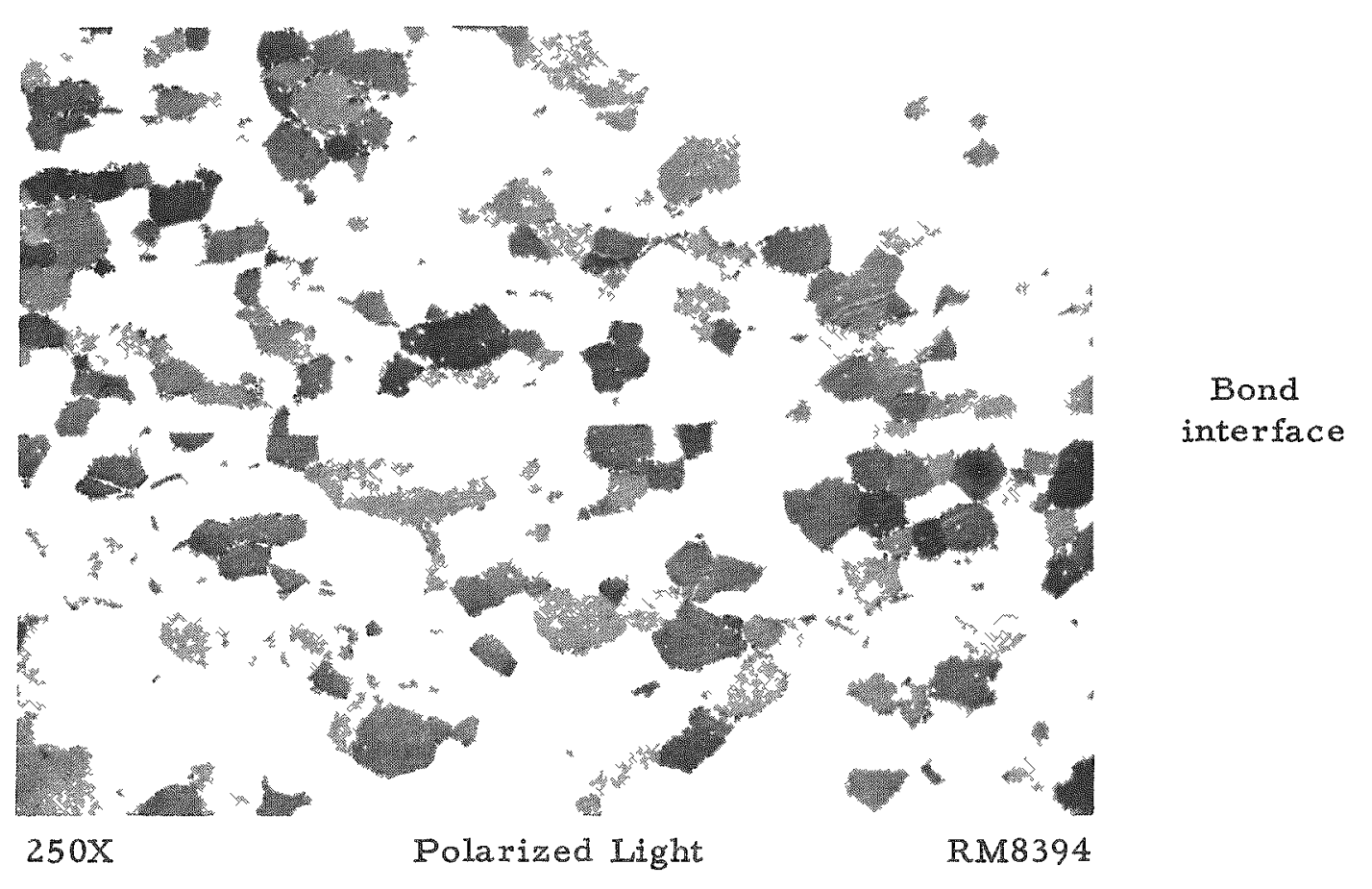

FIGURE 13. INTERFACE OF TYPICAL ZIRCALOY-TO-ZIRCALOY BONDED SPECIMEN IN WHICH PICKLING WAS USED FOR SURFACE PREPARATION

Cold-rolled stock with 0.004 in. of surface metal removed with bifluoride solution. Pressure bonded at $1550 \mathrm{~F}$ for $4 \mathrm{hr}$ at $10,000 \mathrm{psi}$.

Bonding of Abraded Surfaces

The best surface-preparation method investigated for the economical use of materials is the removal of a few mils from the specimen surface with an abrasive belt. For proper surface finishing, the same principles must be followed as for grinding of zirconium(5): using a silicon carbide grit, and abrading under oil at an abrasive speed of 1500 to $3000 \mathrm{sfm}$ instead of the higher speeds normally employed for finishing steel. Initially, specimens were surface prepared by wet hand abrading to determine if an abrading method would yield a surface suitable for pressure bonding. These specimens were evaluated and the data are contained in Table 4.

As can be seen in Table 4, some contamination was not removed during wet hand abrading; however, sufficient grain growth was observed to produce specimens which exhibited good bond strength and relatively good corrosion properties. These results prompted a detailed investigation of the machine belt-abrading process.

During the investigation of the machine belt-abrading process, all variables such as belt speed, coolants, belt grit size, type of grit, and amount of metal removal were considered. Each variable was investigated to obtain the optimum conditions for surface preparation that would result in well bonded Zircaloy -2 surfaces. A sketch of the machine is illustrated in Figure 14.

Both alumina and silicon carbide belts with different grit sizes were employed with varying speeds during the initial tests. The best results were obtained with a 60-grit silicon carbide belt. Extensive embedding of grit in the Zircaloy-2 was observed when alumina belts were used. This is evidenced in Table 5 where the bonded specimen was observed to be severely contaminated and was observed to have only 
TABLE 4. EVALUATION OF BONDED ATMOSPHERE-MELTED COLD-ROLLED ZIRCALOY-2 SPECIMENS SURFACE CONDITIONED BY ABRADING

\begin{tabular}{|c|c|c|c|c|}
\hline \multicolumn{2}{|c|}{ Surface Preparation } & \multirow{2}{*}{\multicolumn{2}{|c|}{ Metallographic Evaluation }} & \multirow[b]{3}{*}{$\begin{array}{l}\text { Corrosion-Test Results } \\
\text { (3 Days in } 750 \text { F Steam) }\end{array}$} \\
\hline \multirow{2}{*}{$\begin{array}{c}\text { Metal } \\
\text { Removed, } \\
\text { in. }\end{array}$} & \multirow[b]{2}{*}{ Method } & & & \\
\hline & & Contamination & $\begin{array}{c}\text { Grain Growth, } \\
\text { per cent }\end{array}$ & \\
\hline 0.001 & Hand abrasion & Slight & 0 & $\begin{array}{l}\text { Intermittent oxides } \\
\text { along the interface }\end{array}$ \\
\hline 0.001 & Hand abrasion & Slight & 20 & $\begin{array}{l}\text { Spots of oxide along the } \\
\text { interface }\end{array}$ \\
\hline 0.0015 & Hand abrasion & Very faint & 25 & No attack \\
\hline 0.002 & Hand abrasion & Slight & 40 & $\begin{array}{l}\text { Spots of oxide along the } \\
\text { interface }\end{array}$ \\
\hline 0.002 & Abrasion wheel & Slight & 50 & No attack \\
\hline
\end{tabular}




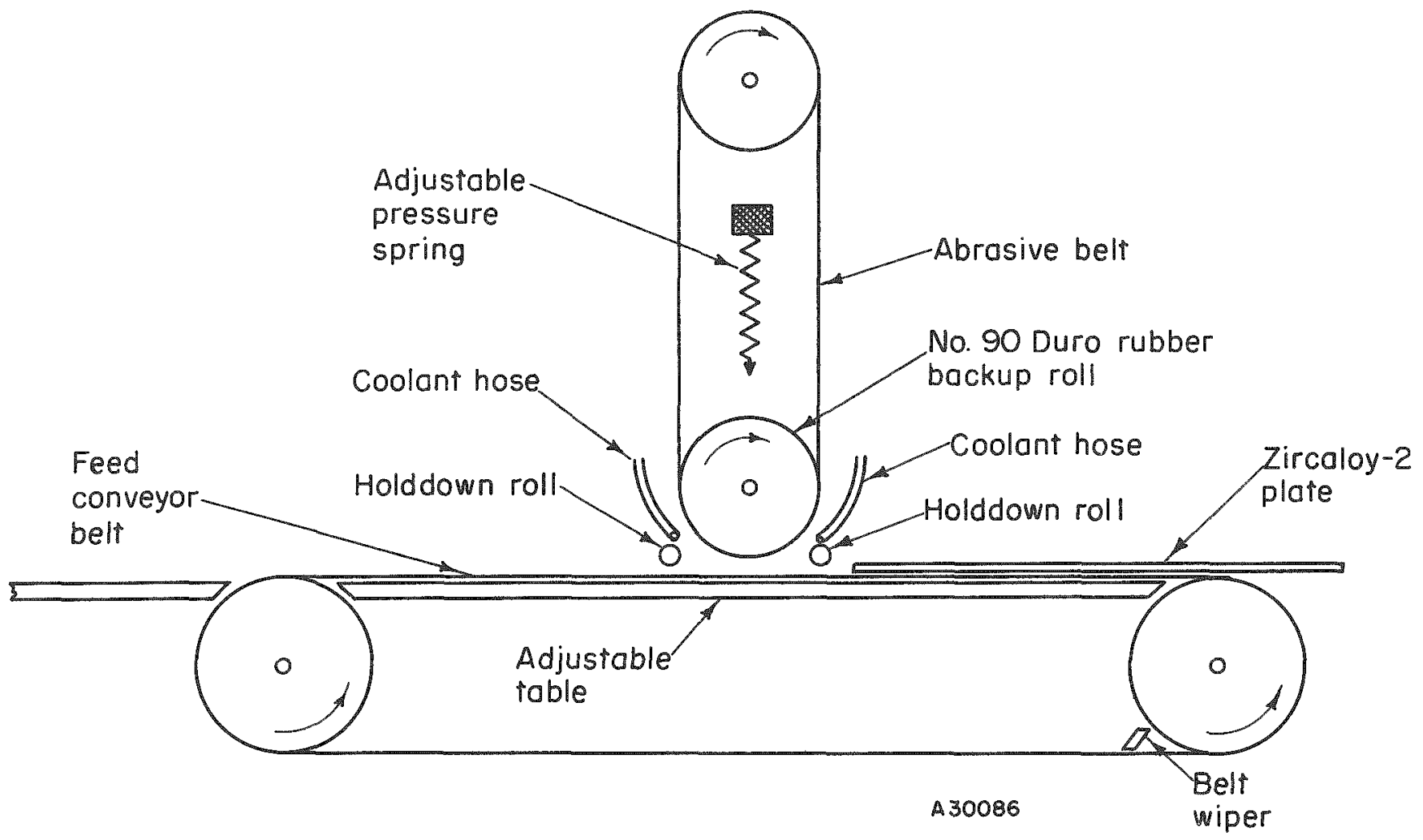

FIGURE 14. SRETCH OF THE MACHINE BELT ABRADER 
20 per cent grain growth across the original bond interface after pressure bonding. An investigation of belt speeds resulted in the selection of $2750 \mathrm{sim}$ for the hot-rolled Zircaloy -2 and 2000 sfm for the cold-rolled Zircaloy-2 at a stock feed of 4 ft per min.

Sulfonated oil was determined to be a better coolant than wate for the machine belt-abrading operation. A more consistent surface finish was obtained with less localized surface oxidation. The belt life was also longer by a factor of 5 relative to the life obtained with other coolants.

The amount of surface metal removed by belt abrading should be between 0.0005 and 0.001 in. per pass to produce the best surface finish with the least amount of recontamination of the Zircaloy -2 surface. The belt life is greatly increased with this amount of metal xemoval as compared with 0.0015 to 0.0025 in. of metal removal per pass. Excellent surfaces for bonding were normally obtained with a total metal removal of 0.002 to $0.003 \mathrm{in}$. Hot-rolled stock that is extensively oxidized requires 0.002 to 0.005 in. of total metal removal.

Fox the cladding of flat-plate type elements containing a metallic core, it is apparent that the belt-abrading process for the preparation of Zircaloy-2 surfaces produced bonds equivalent to those obtained with carefully machined surfaces. A bond obtained with properly abraded surfaces is illustrated in Figure 15. The complete grain growth is apparent in this photomicrograph. Belt abrading is a relatively low-cost operation that is adaptable to production. The most consistent bonds of good integrity were obtained by this process, and this surface preparation was used in the production. of the large-scale specimens.

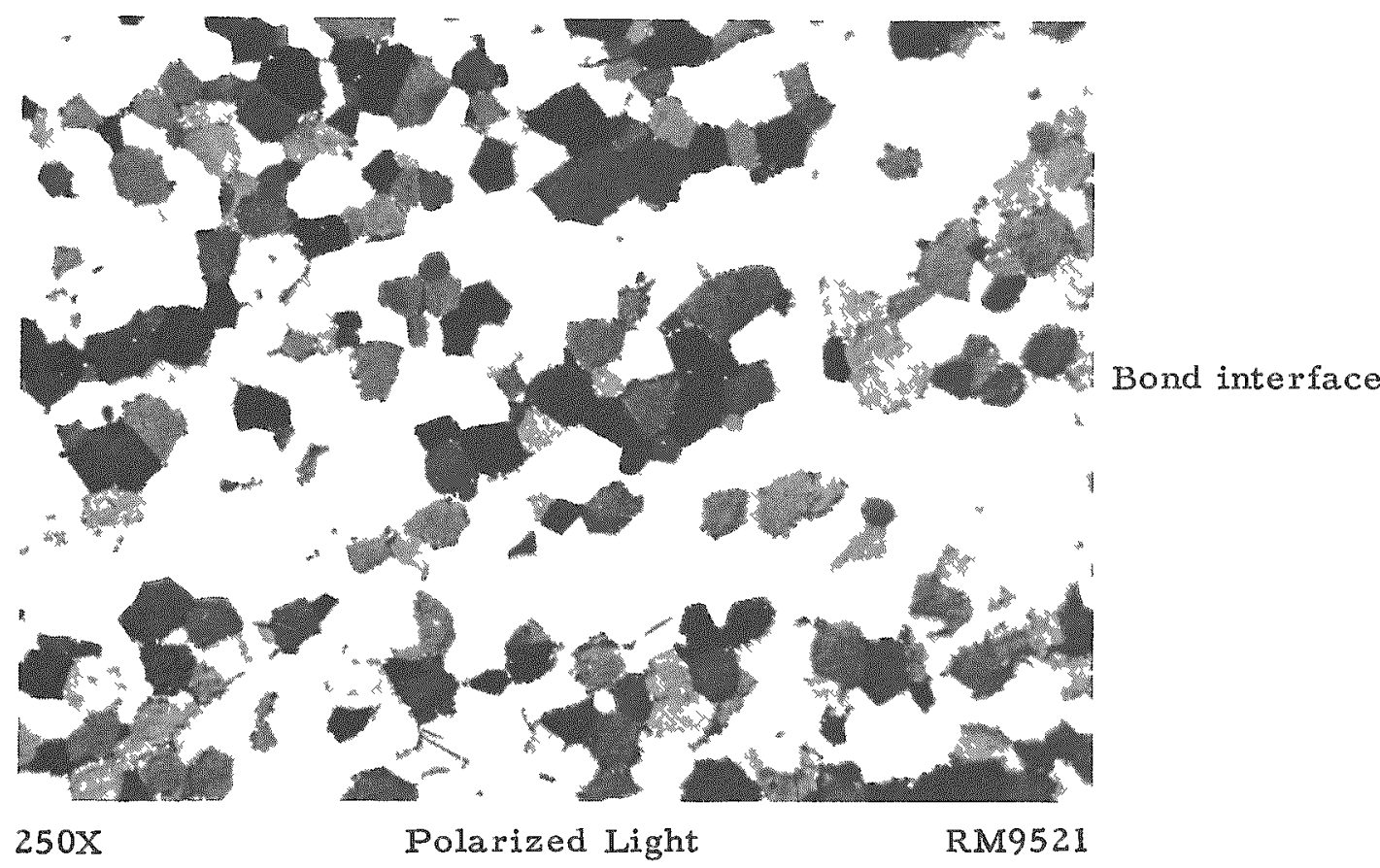

FIGURE 15. INTERFACE OF ZIRCALOY-TO-ZIRCALOY BONDED SPECIMEN WITH SURFACES PREPARED BY BELT ABRADING

0.003 in. of surface metal was removed by machine belt abrading from the cold-rolled stock. Pressure bonded at $1550 \mathrm{~F}$ for $4 \mathrm{hr}$ at $10,000 \mathrm{psi}$. 
TABLE 5. THE EFFECT OF BELI-ABRADING VARIABLES ON ZIRCALOY-IO-ZIRCALOY BONDS ACHIEVED BY GAS-PRESSURE BONDING

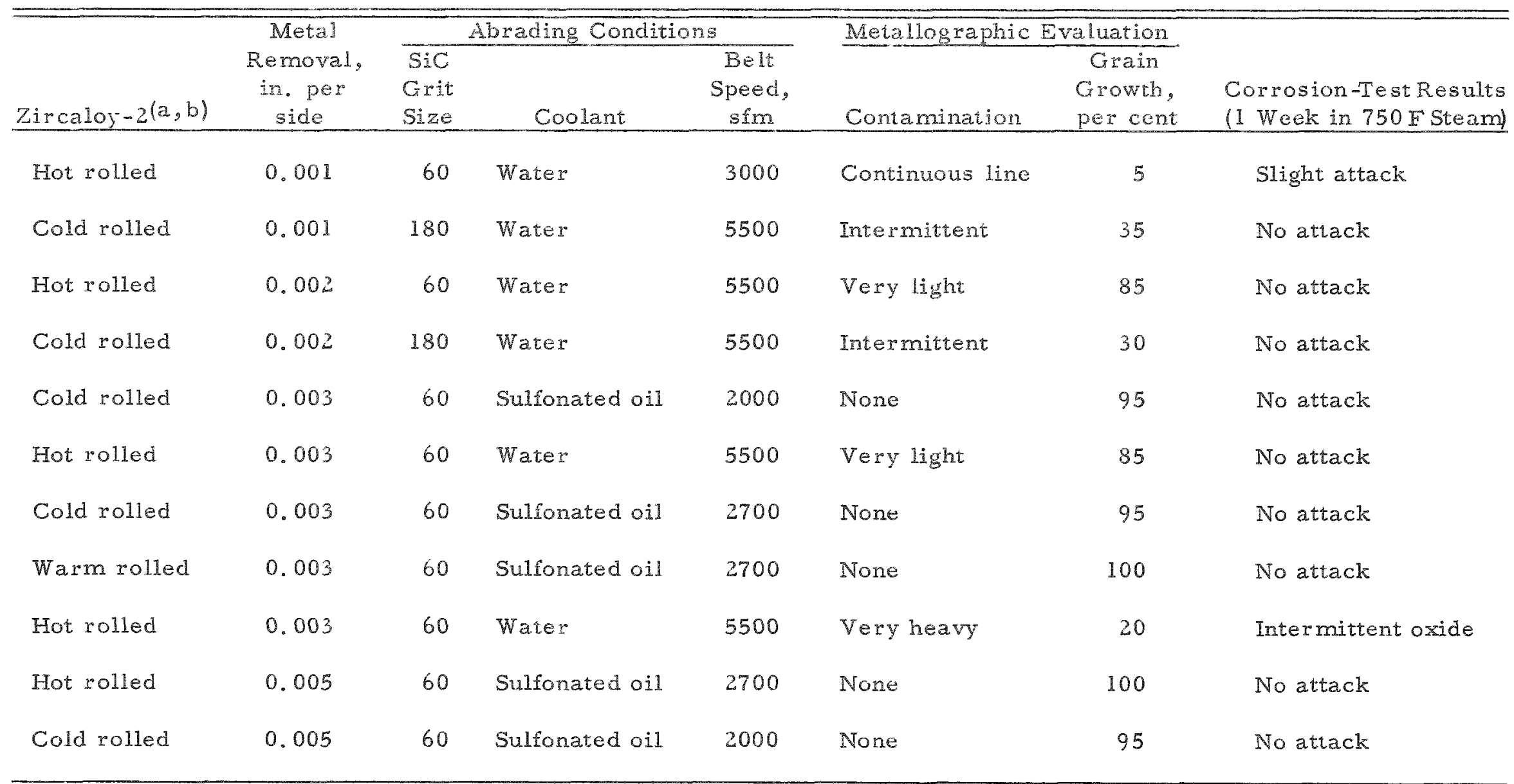

(a) The cold-rolled material was cold reduced 3 to 1 . The hot -rolled nuterial was rolled at $1550 \mathrm{~F}$ and was covered with a much heavier scale than the warm -rolled material rolled at $1150 \mathrm{~F}$.

(b) All material was atmosphere melted Zircaloy-2. 
Evaluation of Miscellaneous Surface Preparations

Barrel finishing was investigated as a means of surface preparing Zircaloy for bonding. Zircaloy-2 plates were held in a fixture and barrel finished in a slurry containing alumina chips. A bright smooth finish was produced; however, bond interfaces produced with sheets of Zircaloy-2 surface prepared in this manner were highly contaminated. The difficulties encountered in controlling distortion of the Zircaloy-2 during barrel finishing and the problems as sociated with contamination were too extensive to warrant additional investigation of the barrel-finishing process. Figure 16 illustrates a bond obtained between a set of barrel-finished Zircaloy-2 plates.

A cursory study was made of wire brushing as a method of surface preparation. This method of surface preparation was accomplished by hand feeding the Zircaloy -2 plates under a rotating wire brush. The contamination appeared to be removed in some areas and piled up in others, as indicated by spotty bonds and spotty corrosion resistance of the bond interface. A typical bond obtained between two wire-brushed Zircaloy-2 surfaces is shown in Figure 17.

Development of Gas-Pressure-Bonding Technique for Preparing 2 by 2 by $20-I n$. Flat-Plate Assemblies

Belt-abraded Zircaloy -2 components and uranium $-5.5 \mathrm{w} / 0$ zirconium core components were used in the development studies concerned with preparing 2 by 2 by 20 -in. flat-plate assemblies by pressure bonding. The 2 by 2 by 20 -in. assemblies embodied 16 fuel plates and 15 coolant channels. The dimensions employed for each component are prosented in a drawing of a reference assembly in Figure 18.

Initially, development of a suitable component design and methods of loading and jigging was undertaken and the use of pieced frame components rather than machined frames was investigated. Canning techniques for these larger assemblies were also studied. Assemblies 2 by 2 by 6 in. were utilized for these preliminary investigations. The assemblies contained 16 fuel plates and 15 coolant channels. Uranium-22 w/o zirconium was used as the core alloy. Zircaloy-2 strips were used in these assemblies to form a pieced picture frame and to form the side supports for the coolant channels. Ti-Namel pressure plates $0.080 \mathrm{in}$. thick were placed at the top, bottom, and ends of the assembled components to take up any excess deformation that might occur by flow at the container edges. The assemblies contained no internal or external jigging other than the pressure plates. An assembly of this type was bonded at $1550 \mathrm{~F}$ for $5 \mathrm{hr}$ at $10,000 \mathrm{psi}$. After the bonding cycle, it was removed from its container and its spacers pickled out as previously discussed. Excellent channel spacing and dimensional control was exhibited except at the end next to the evacuation tube. At this point, a slight amount of plate deformation was observed as a result of the extrusion of the Ti-Namel end pressure plate and components into the evacuation tube. The sides of the assembly were relatively smooth and square, indicating that no external jigging would be necessary. Figure 19 shows a typical Zircaloy-to-Zircaloy bond and Zircaloy-tozirconium-22 w/o uranium bond. Complete grain growth across all the original Zircaloy -2 interfaces was obtained. 
32

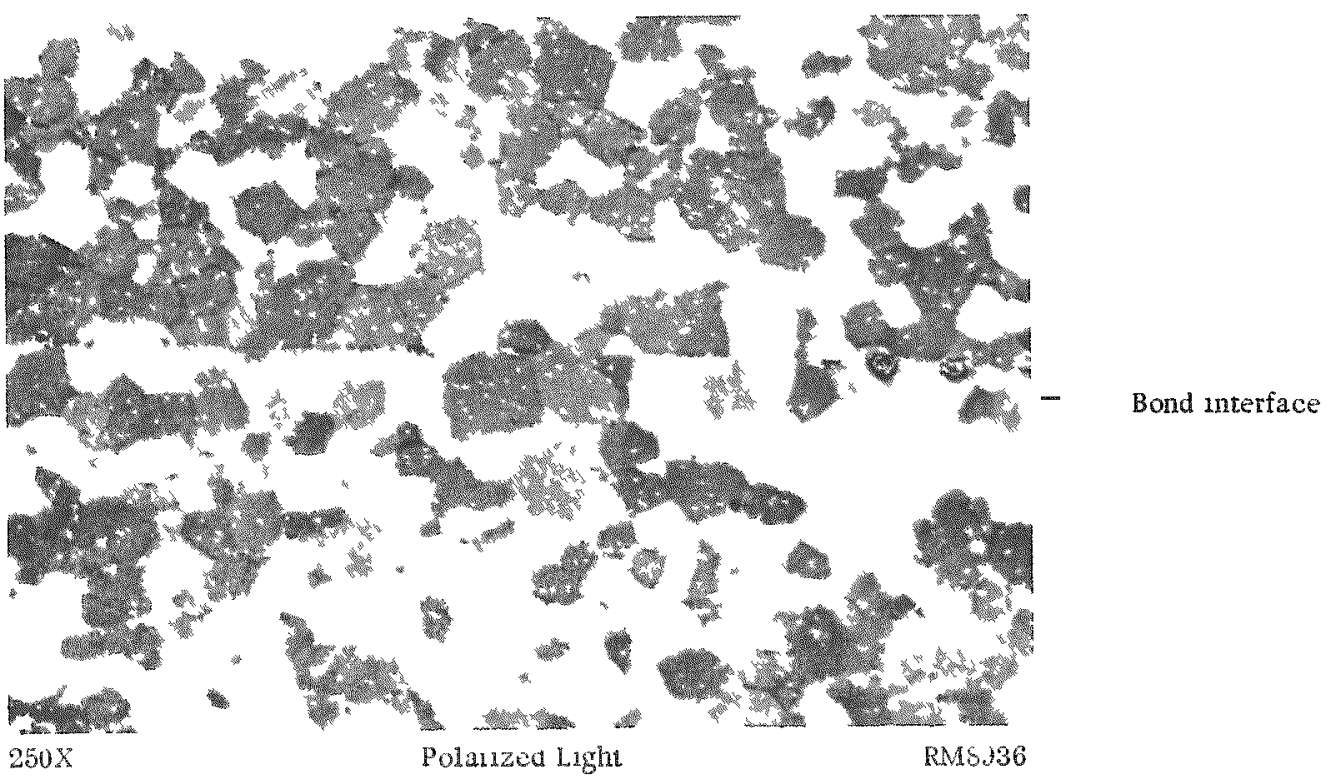

FIGURE 16. INITRFACL OI LIRCALOY-TO-ZIRCALOY BONDED SPECIMEN IN WHICH BARREL FINISHING WAS USED FOR SURFACE PREPARATTON

0.0003 in. of sunace inetal was removed from the coldwrolled stock by barrel finishng in an $\mathrm{Al}_{2} \mathrm{O}_{3}$

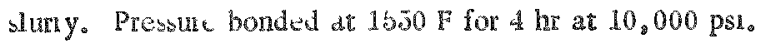

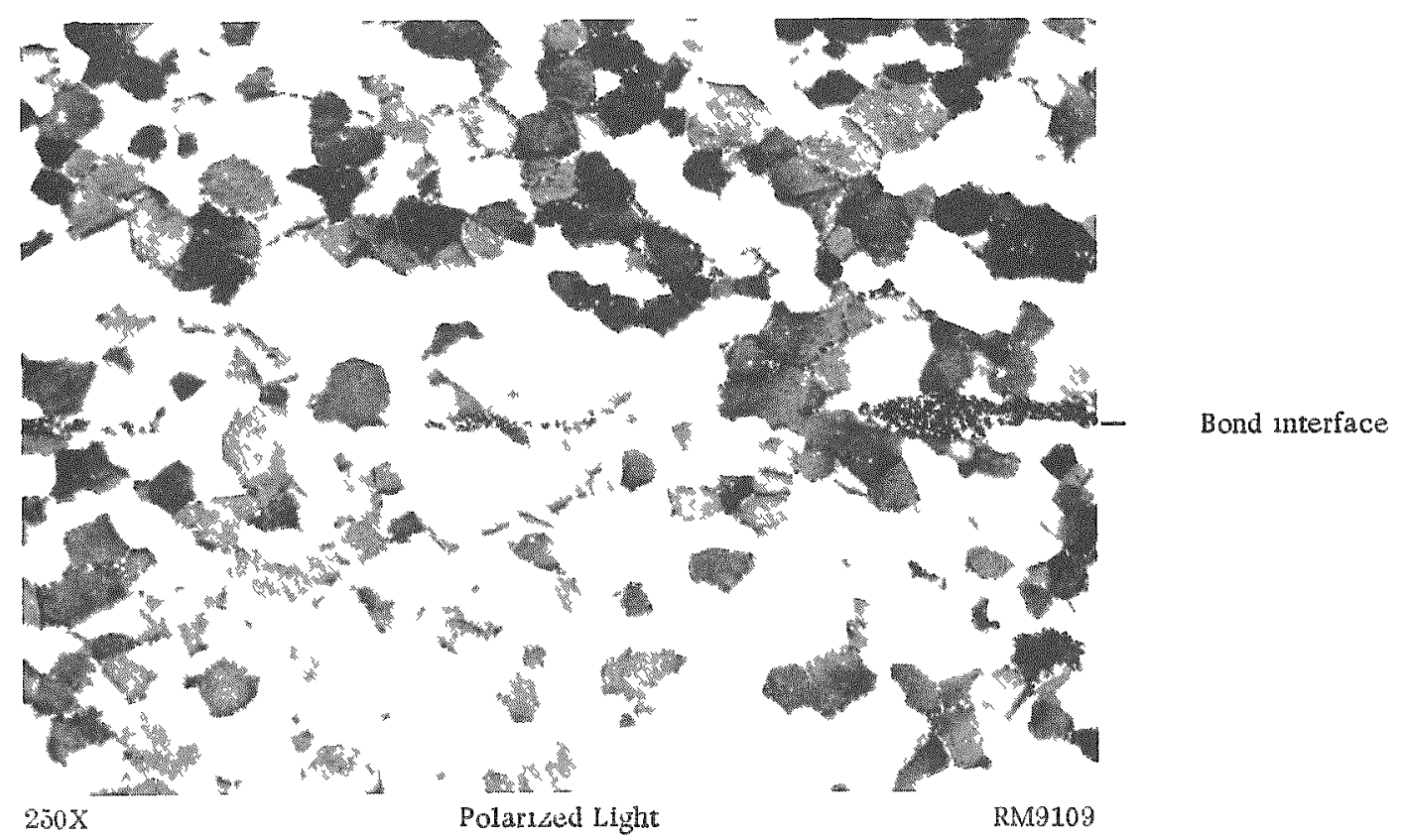

HIGUR 17. INTEISACE OF LNC 1 LOY - TO -ZIRCALOY SPECIMEN BONDED AFIER WIRE BRUSHING

$0.0025 \mathrm{n}$. of surface metal was removed from the cold-rolled stock by wire brushing. Pressure bonded at $1550 \mathrm{~F}$ for $4 \mathrm{hr}$ at $10,000 \mathrm{psi}$. 

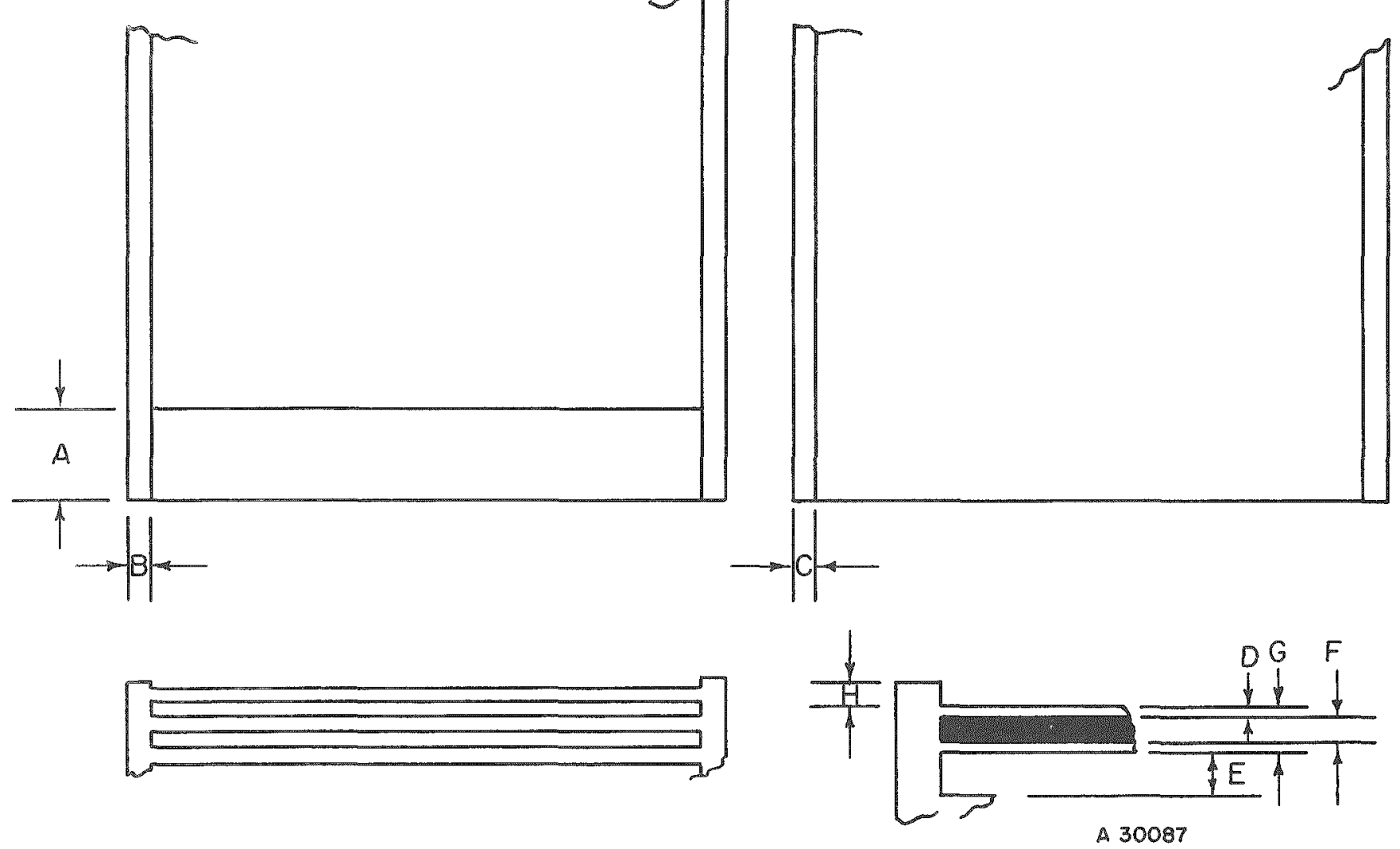
A. Wirlh of irame at the ends
$0.150 \mathrm{in}$. $\min$ to $0.500 \max$
B. Width of frame at the sides
$0.120 \mathrm{in}$. $\min$ to $0.180 \mathrm{max}$
C. Width of structural side supports
$0.120 \pm 0.025 \mathrm{in}$.
D. Cladding thickness
$0.014 \pm 0.006 \mathrm{in.}$ local, $\pm 0.002 \mathrm{in}$. avg.
E. Channel spacing
$0.051 \pm 0.005 \mathrm{in}$.
F. Coine thickness
G. Plate thickness
$0.045 \div 0.006$ in local, \pm 0.002 in. avg.
H. 1 '2 channel spacing
$0.073 \mathrm{in.}$
Length 20 in.
Widuh $\quad 2.000 \pm 0.004 \mathrm{in}$.
Number of plates 16

FIGURE 18. DIMENSIONAL-TOLERANCE SPECIFICATIONS FOR REFERENCE ASSEMBLY 


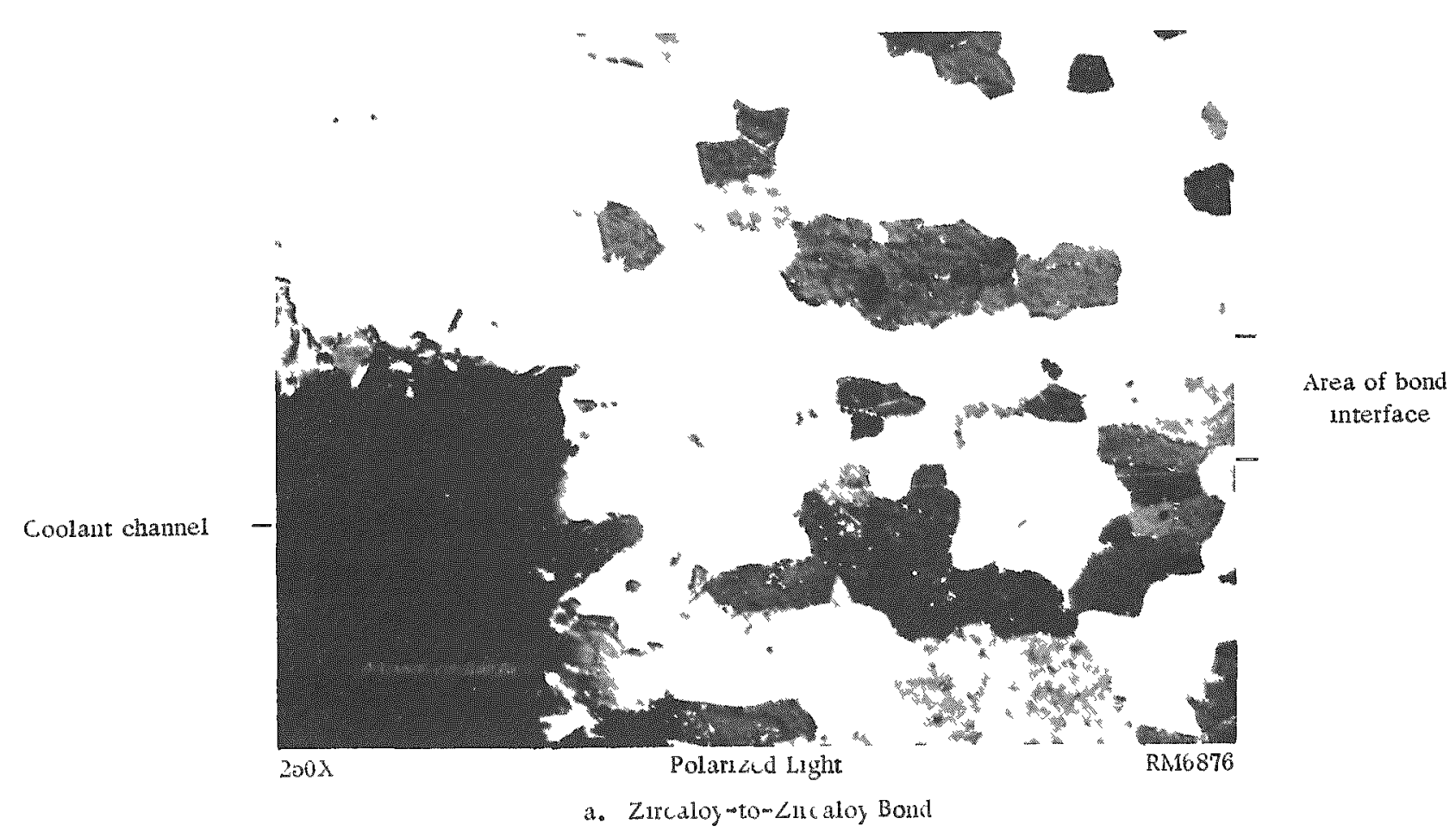

- Lincaloy-2

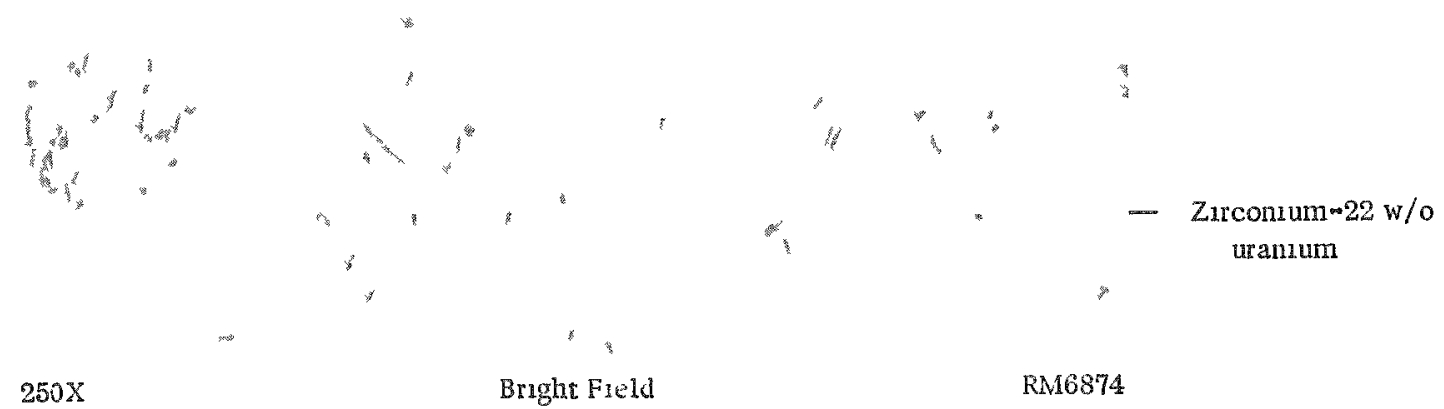

b. Zucaloy $-t 0-Z 1$ rconum -22 w/o Urantum Bond

FIGURE 13. TYPICAL BONDS OBTAINCD IN A GA $>$ APRESSURE-BUNDED ASSEMBLY CONTAINING MACHINED COMPONENTS 2 by 2 by $6 m$. assembly pressure bonded at $1550 \mathrm{~F}$ for $5 \mathrm{hr}$ at 10,000 psi。 
A 2 by 2 by 6 -in. assembly was pressure bonded in a stainless steel container with only end pressure plates at $1550 \mathrm{~F}$ for $5 \mathrm{hr}$ at $10,000 \mathrm{psi}$. The extrusion of the end pressure plate and assembly into the evacuation tube during pressure bonding was minimized by placing an undersize stainles steel rod into the evacuation tube priox to pressure bonding. Excellent dimensional control was achieved except for the edges of the half channels, which flowed into the flanges of the container as shown in Figure 20. From results obtained with this specimen, il was obvious that top and bottom pressure plates were necessary to prevent distortion of the half channels. This assembly was sectioned and a dimensional survey was made. The fuel-plate and channeJ thicknesses were constant within $0.003 \mathrm{in}$. and the average increase in channel width was 0.003 in. The assembly is shown in Figure 21 with $0.250 \mathrm{in}$. removed from one end to expose the cores.

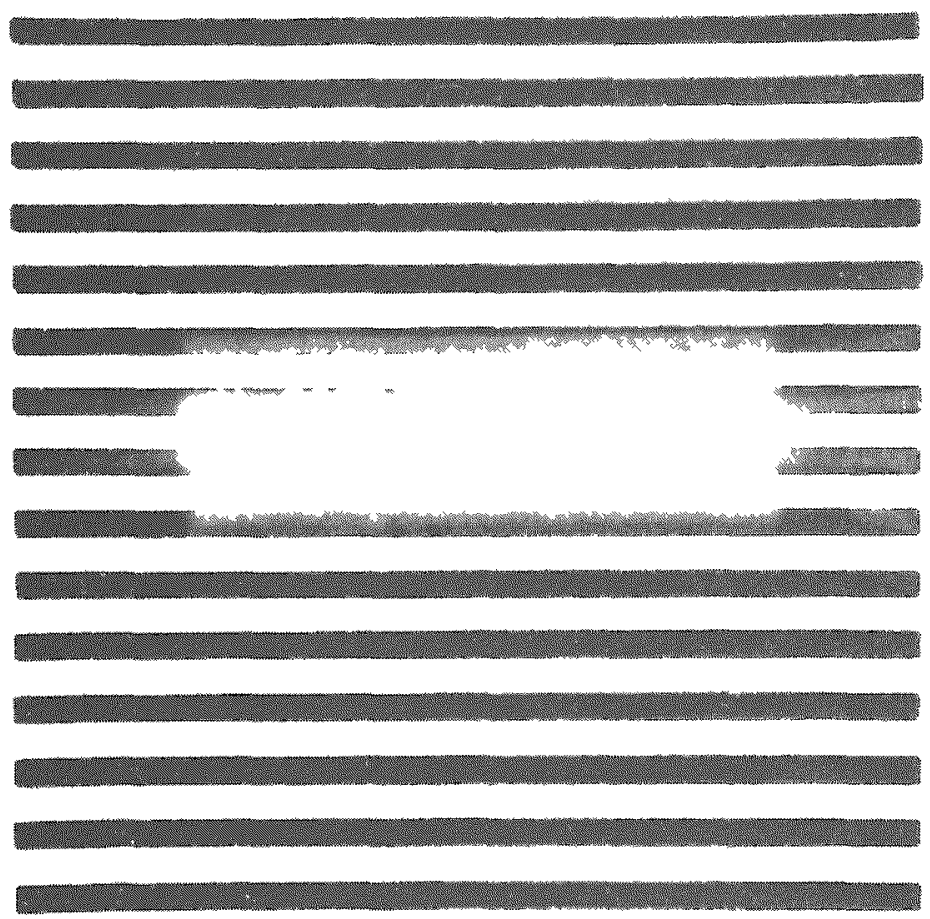

$\mathbf{N} 45669$

FIGURE 20. TRANSVERSE SECTION OF A 2 BY 2 BY 6-IN. FLAT-PLATE ASSEMBLY PRESSURE BONDED WITHOUT TOP AND BOTTOM PRESSURE PLATES

The deformed half channels on the top and bottom of this assembly were caused by flow into the flanges of the stainless steel container; otherwise the specimen exhibited excellent dimensional uniformity. Pressure bonded at $1550 \mathrm{~F}$ for 5 hr at 10,000 psi.

After a 72-hr corrosion test in 680 Frater, no bond-line attack was observed, but some corrosion attack on the surface of the Zircaloy-2 was noted. This surface attack appeared to be caused by iron diffusion from the Ti-Namel. 


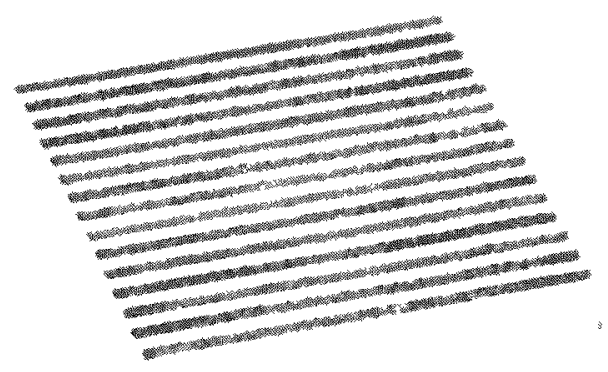

$\mathrm{N} 45700$

FIGURE 21. FLAT PLATE 2 BY 2 BY 6 $\mathrm{mN}$. ASSEMBLY CONTAINING COLD -ROLLED COMPONENTS

This is an overwall view of the assembly shown in Figure 20. Enough material has been removed from the end shown to expose the cores. Pressure bonded at $1550 \mathrm{~F}$ for 5 hr at 10,000 psi. 
Components for additional as semblies were fabricated from cold-rolled material which had approximately 0.005 in. of surface material removed by machining. The size and number of components for a 2 by 2 by 6 -in. as sembly are shown in Table 6.

TABLE 6. COMPONENTS FOR A 2 BY 2 BY 6-IN. FLAT-PLATE ASSEMBLY FOR DEVELOPMENT STUDIES(a)

\begin{tabular}{|c|c|c|c|c|c|}
\hline \multirow{2}{*}{$\begin{array}{l}\text { Number of } \\
\text { Components }\end{array}$} & \multirow[b]{2}{*}{ Type of Component } & \multirow[b]{2}{*}{ Material } & \multicolumn{3}{|c|}{ Size $(b)$, in. } \\
\hline & & & Thickness & Width & Length \\
\hline 32 & Cover & Zircaloy -2 & 0.020 & 2. 000 & 6.000 \\
\hline 32 & Frame side & Zircaloy-2 & 0.050 & 0.140 & 6.000 \\
\hline 32 & Frame end & Zircaloy -2 & 0.050 & 0.140 & 1.720 \\
\hline 16 & Core & $\mathrm{Zr}-22 \mathrm{w} / \mathrm{O} \mathrm{U}$ & 0.050 & 1.720 & 5.720 \\
\hline 30 & Full support & Zircaloy-2 & 0.050 & 0.140 & 6.000 \\
\hline 15 & Full channel & Ti-Namel & 0.050 & 1.720 & 6.000 \\
\hline 2 & Top and bottom plates & Ti-Namel & 0.080 & 2.000 & 6.000 \\
\hline 3 & End plate & Ti-Namel & 0.080 & 2.000 & 2.370 \\
\hline
\end{tabular}

(a) All these assemblies have 157 components plus 5 pressure plates.

(b) All tolerances are \pm 0.001 in. except the thickness which is \pm 0.0005 in.

These 2 by 2 by 6 -in. assemblies were pressure bonded at $1560 \mathrm{~F}$ for $5 \mathrm{hr}$ at $10,000 \mathrm{psi}$. In these assemblies, the Ti-Namel channel inserts and pressure plates were flash chromium plated. This was done in an effort to prevent iron diffusion into the Zircaloy-2.

Excellent dimensional control was achieved with these assemblies. The placing of a stainless steel pressure plate, as illustrated in Figure 8, between the evacuation tube and the end Ti-Namel pressure plate eliminated the extrusion of the pressure plate and assembly into the evacuation tube during bonding.

The ends of these bonded assemblies were polished and studied by metallography. The assemblies appeared well bonded with about 90 per cent grain growth across the original bond interface and little or no evidence of iron diffusion. Examination of the as semblies after corrosion testing in $680 \mathrm{~F}$ water for $72 \mathrm{hr}$ revealed no apparent corrosion attack along any of the bond interfaces or on any of the Zircaloy-2 surfaces. One assembly was corrosion tested for a total of 28 days in $680 \mathrm{~F}$ water, after which time it was carefully examined and sectioned. There was no bond-line corrosion attack visible over the entire specimen; however, small areas in some of the channels had a slight frosty corrosion product. It is believed that this corrosion resulted from incomplete solution of the chromium-plated Ti-Namel spacers. The remainder of the specimen exchibited excellent corrosion resistance. 
The components for a 2 by 2 by 20 -in. assembly, $A M G-1$, were fabricated from atmosphere-melted hot-rolled Zircaloy -2 and zirconium-5.5 w/o uranium cores. This material was machine belt abraded, removing 0.003 in. of metal from the flat sur faces. The size and number of components used in the 2 by 2 by 20 -in. assemblies are given in Table 7. The channel inserts and pressure plates were fabricated from coldrolled and machine belt-abraded Ti-Namel and given a flash chromium plate.

TABLE 7. COMPONENTS FOR THE 2 BY 2 BY 20 -IN. FLAT-PLATE ASSEMBLIES

\begin{tabular}{cllccc}
\hline \hline $\begin{array}{l}\text { Number of } \\
\text { Components }\end{array}$ & Type of Component & Material & Thickness & Width & Length \\
\hline 32 & Cover & Zircaloy -2 & 0.014 & 2.000 & 20.000 \\
32 & Frame side & Zircaloy-2 & 0.045 & 0.150 & 20.000 \\
32 & Frame end & Zircaloy-2 & 0.045 & 0.500 & 1.700 \\
16 & Core & Zr-5.5 $/ 00$ & 0.045 & 1.700 & 19.000 \\
30 & Channel support & Zircaloy-2 & 0.051 & 0.140 & 20.000 \\
15 & Channel spacer & Ti-Name1 & 0.051 & 1.720 & 20.000 \\
\hline
\end{tabular}

(a) All tolerances on thickness held to \pm 0.0005 in. and all others held to \pm 0.002 in.

The time at temperature for this assembly was estimated to be $3-1 / 2$ to $4 \mathrm{hr}$. The assembly was removed from the autoclave after a furnace failure; consequently, the specimen had to be reloaded and the run completed. The temperature was between 1510 and $1575 \mathrm{~F}$ at various locations. The assembly was removed from its container and the Ti-Namel spacers were dissolved by acid solution. A metallographic section was taken from each end of the bonded assembly for examination and evaluation of the bond integrity. The metallographic examination of these sections revealed that very good Zircaloy-to-Zircaloy bonds were obtained. The assembly was subjected to a 3-day $680 \mathrm{~F}$ water corrosion test. Excellent corrosion resistance was observed.

The assembly appeared to have good dimensional stability except that it possessed a slight camber (approximately $1 / 8 \mathrm{in}$ ) along the length of the specimen. This may have been produced by the thermal gradient existing along the assembly during the bonding cycle.

Three views of this as sembly are shown in Figures 22, 23, and 24. The squareness and relatively smooth sides, illustrated in Figures 23 and 24 , indicate that it should be possible to use pressure-bonded assemblies without any subsequent machining. 


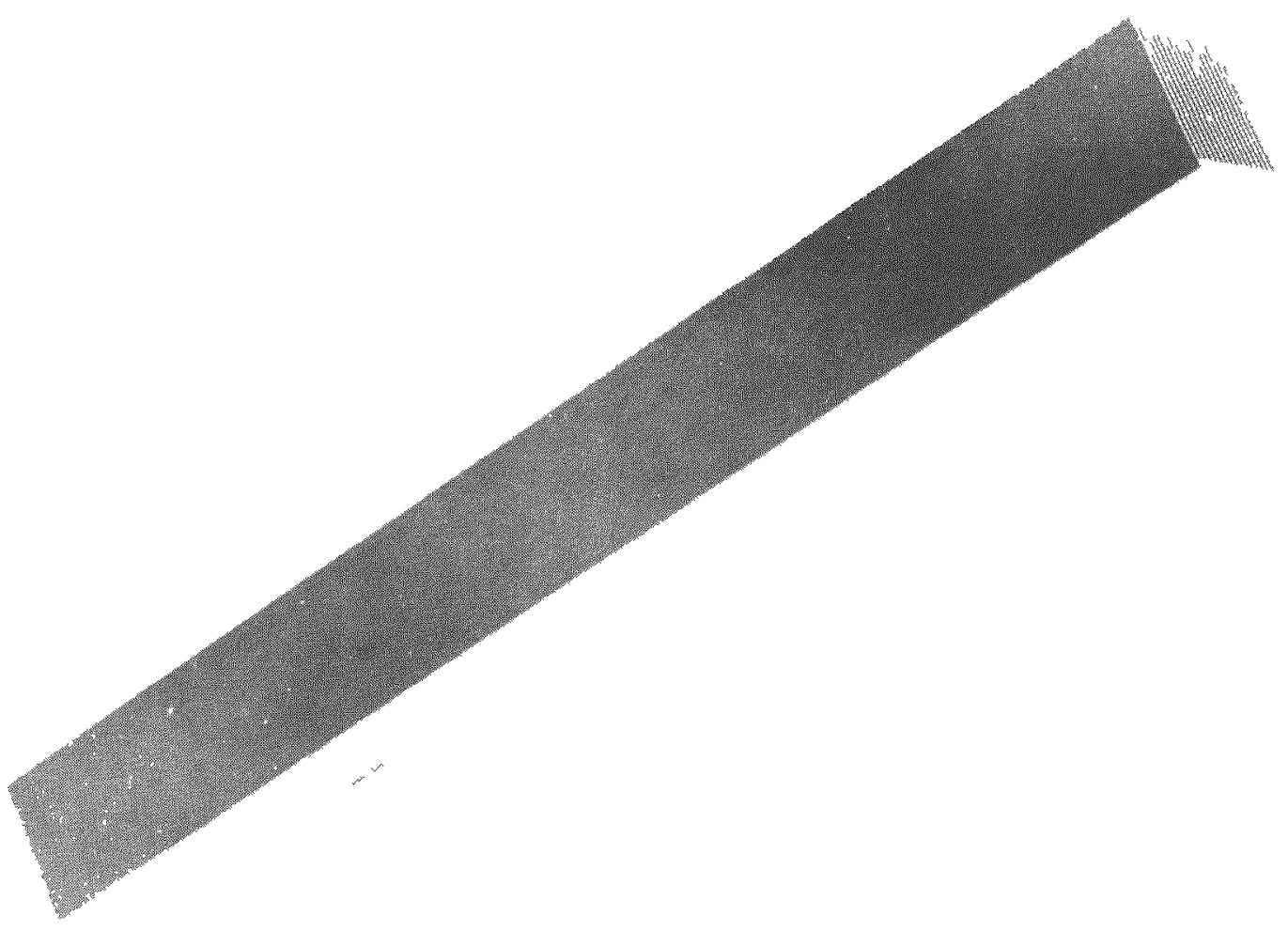

N49183

FIGURE 22. GAS $\leadsto$ PRESSURE-BONDED 2 BY 2 BY 20-IN. FLAT -PLATE ASSEMBLY WITH 16 FUEL PLATES 


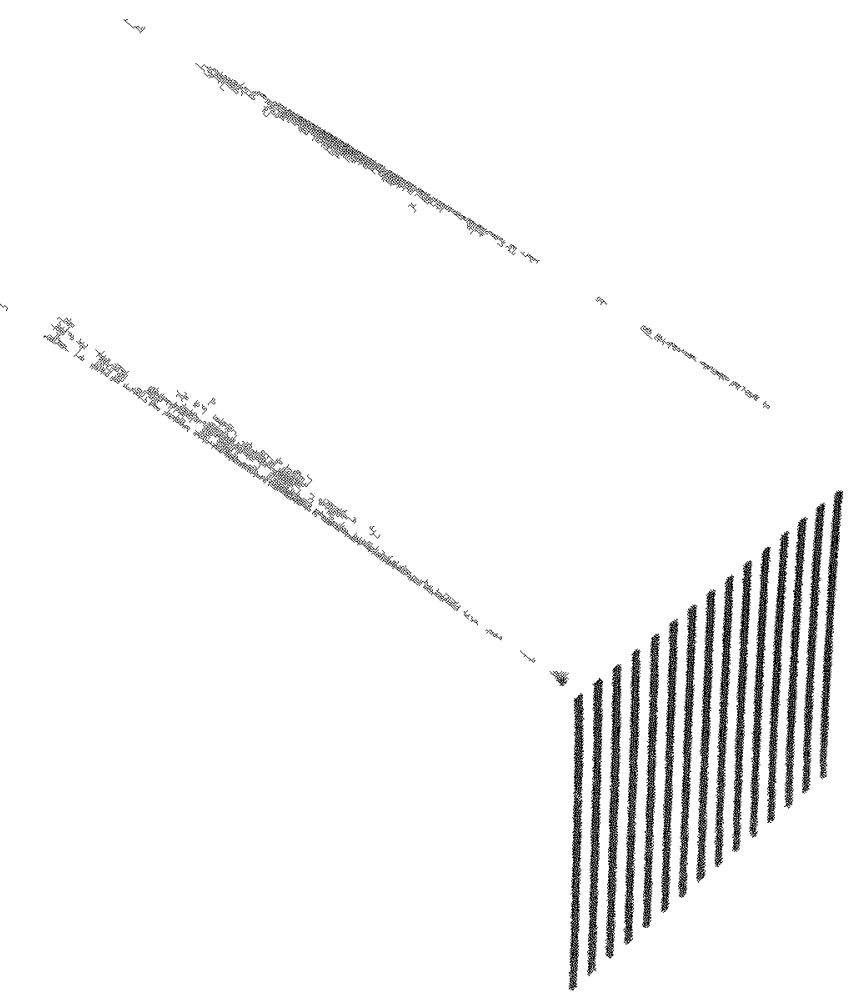

$N 48948$

FIGURE 23. SIDE VIEW OF A GAS PRESSURE-BONDED 2 BY 2 BY 20 - IN. FLAT $\leadsto$ PLATE ASSEMBLY 


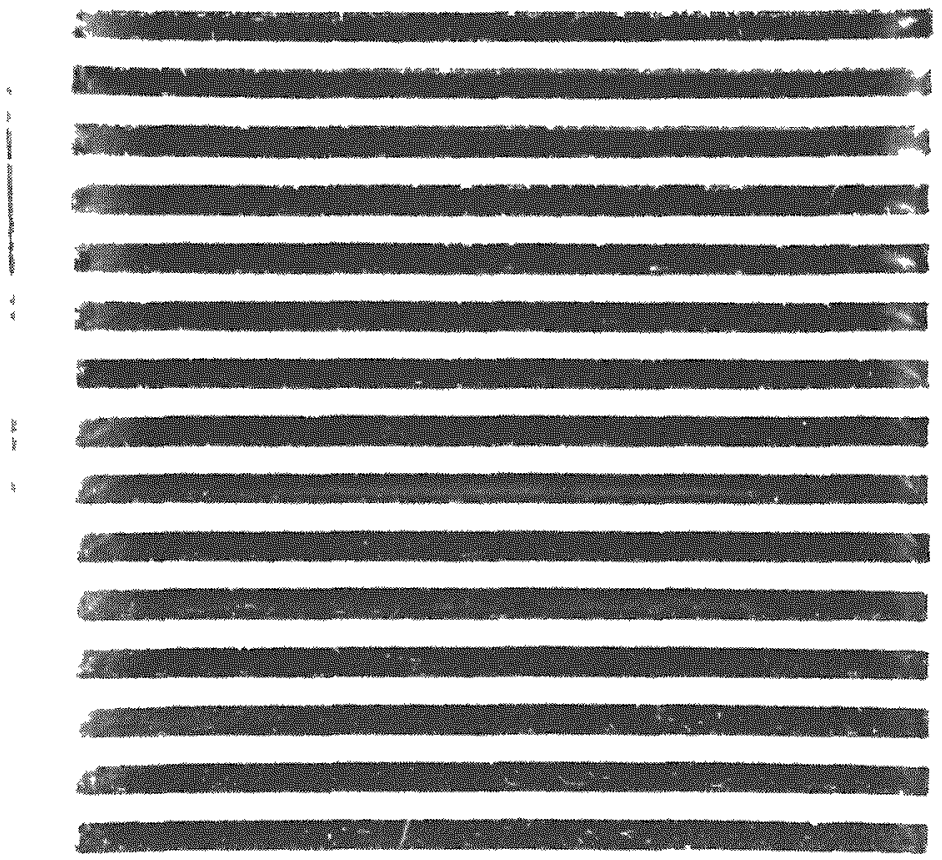

N49185

FIGURE 24. END VIEW OF A GAS-PRESSURE-BONDED 2 BY 2 BY 20-IN. FLAT -PLATE ASSEMBLY WITH 16 FUEL PLATES 
The components for two additional 20-in. assemblies (VM-20-1 and VM-20-2) were prepared from hot-xolled vacuum-melted Zircaloy -2 and zirconium $-5.5 \mathrm{w} / \mathrm{o}$ uranium cores. The material was surface finished by the machine belt-abrading proces s with 0.003 to 0.004 in. of surface metal being removed.

The two assemblies were pressure bonded for a period of $4 \mathrm{hr}$ at a temperature of $1550 \mathrm{~F}$ and a pressure of 10,000 psi. A uniform heat zone was maintained over the entire length of Assembly VM-20-2 to within $\pm 10 \mathrm{~F}$. However, the heat zone during the bonding of Assembly VM-20-1 varied about $50 \mathrm{~F}$ and the temperature of the specimen reached $1580 \mathrm{~F}$ for a short period. A metallographic specimen cut from each end of this assembly revealed only partial bonding, and iron diffusion was observed in the Zircaloy -2 adjacent to the channels. The assembly appeared to have good dimensional control and no dimensional distortion could be observed along the length or width of the as sembly.

A metallographic examination of the specimen bonded with satisfactory temperature control conditions, $\mathrm{VM}-20-2$, revealed that complete metallurgical bonding was achieved between all of the components. A dimensional evaluation of this as sembly revealed that excellent dimensional control was achieved.

All three of the 2 by 2 by 20 -in. assemblies were sent to Bettis for further evaluation. The results of this evaluation are presented in the Appendix.

\section{SUMMARY AND CONCLUSIONS}

The process of gas-pressure bonding was developed for the fabrication of flatplate as semblies without the intermediate step of making individual fuel elements. The research program was completed with the preparation of three excellent quality 2 by 2 by 20 -in. subscale flat-plate assemblies incorporating 16 Zircaloy-2-clad uraniumzirconium alloy fuel plates and 15 coolant channels. The development of this process for bonding of integral flat-plate assemblies in a one-step bonding operation was dependent upon several supplementary developments and refinements of the gas-pressurebonding process.

Because the bond surfaces do not deform, as in coextrusion or roll bonding, the preparation of the surfaces for bonding was especially critical; consequently, it was necessary to develop a method of surface preparation that was economical and one that would produce consistent bonds. The best method developed in this study was surface preparation by machine belt abrading. It was determined that either hot-or coldworked material subjected to a surface metal removal of 0.002 to $0.003 \mathrm{in}$. could be bonded consistently.

Piece components can be employed with this process. By fabricating the piece components to final size before bonding, close inspection of each component can be made and the final dimensions of the bonded assemblies can be closely controlled and significant economies in fabrication can be realized. With this process, it is also possible to obtain good metallurgical bonds at all of the interfaces of the piece components. 


\section{ACKNOWLEDGMENT}

This work was sponsored by the Bettis Laboratory of the Atomic Energy Commission, operated by the Bettis Atomic Power Division of Westinghouse Electric Corporation. The authors wish to express their appreciation to Dr. E. Byron and Messrs. L. Prus, H. Hoge, and S. Porembla for their assistance in the course of this research.

\section{REFERENCES}

(1) Paprocki, S. J., Hodge, E. S., and Boyer, C. B., "The Cladding of Delta-Phase Zir conium Hydride", BMI-1244 (December 27, 1957).

(2) Bridgman, P. W. The Physics of High Pressure, George Bell and Sons, Ltd., London (1949).

(3) Comings, E. W., High Pressure Technology, McGraw-Hill Book Company, Inc., New York (1956).

(4) Simmons, J. T., "The Physical and Thermodynamic Properties of Helium", Wm. R. Whittake Company, Ltd., Engineering and Research Division, Technical Report D-9027 (July 1, 1957).

(5) Lustman, B., and Kerze, F., The Metallurgy of Zirconium, McGraw-Hill Book Company, Inc., New York (1955), p 331.

SJP:ESH:CBB:RWG/ims 


\begin{abstract}
APPENDIX
Reproduction of a Report on

EVALUATION OF PRESSURE BONDED SUBASSEMBLIES
\end{abstract}

H. R. Hoge and L. F. Cochrun

Bettis Atomic Power Division

Westinghouse Electric Corporation 
The three pressure bonded subasembies. MMG, Ma-20-14 and M-20-2 were evaluated for channel spacing, corrosion resistance (including spacer contamination of heat trengrer surfiaces), and bond integrity. After picking in a $50 \% \mathrm{MMO}_{3}$ solution to remove the Thname spacers, the indicated processes were used for evaluation.

AMa-I - Straighten pickle for corrosion test, probe water channels, corroston tert, photoGraph heat transfer surfaces with panoramic camera, sectioned for metallographic investigation of indigidul elements, ultrasonic test individual elements for bond Integrity.

M-20.IS Mrobn water chanels, piekle for corrosion test, probe water channels and corrosion test.

m-20-2 section for metallograph and probe water chands.

M11 operation were performed in accordance with the standard procedures for fabricated

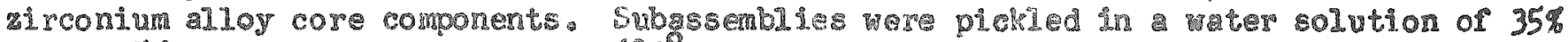
$\mathrm{HO}_{3}$ * $5 \%$ HF, corrosion tested ir $680^{\circ}$ satureated water and probed with split-ball type water channel probe.

Channel Spacing

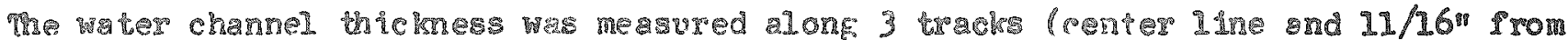

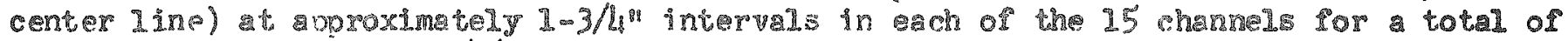
10 reading per track and 450 readings per subassembly. The rap data was aule voluminous and is, therefore, not reproduced; however, the statistical sumnary is shom in pables I and IT. The average chamel spacing and wertinent ranges are sham below.

\begin{tabular}{|c|c|c|c|c|c|}
\hline Subrss & Condton & 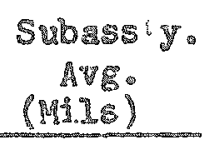 & $\begin{array}{c}\text { overall Fange } \\
\text { of locals } \\
\text { (119.25) }\end{array}$ & $\begin{array}{l}\text { Range or } \\
\text { Magk AVgs. } \\
\text { (MIII) }\end{array}$ & $\begin{array}{l}\text { Range or } \\
\text { Channel Avgs } \\
\text { (ML1s) }\end{array}$ \\
\hline $\mathrm{AMC}=1$ & pickied & 51.3 & 7 & 3.6 & 2.7 \\
\hline VII-20-14 & $\begin{array}{l}\text { Donded } \\
\text { Pickled }\end{array}$ & $\begin{array}{l}49.5 \\
52.3\end{array}$ & $\frac{5}{6}$ & 304 & 1.7 \\
\hline mI 200.2 & Bonded & 49.8 & 6 & 4.6 & 3.0 \\
\hline
\end{tabular}

For comparison purposes, the snecification for the PIF seed allow ange of channel thicknesses of acproximitely $10 \mathrm{mi}$.s and a Loral range rom tha average for a channel of approximately 15 mis. for a total allowable cange of 24 mis. Deviations from normalty of distribution occurred only on the high (thirk channel) side so that the critical thin chamel dimensions could be accurately calculated. It is most important to note that the variation of channel spacing. both local points and avergges. Is vary nearly aqul to the precision of the measuring instrument used and a certaln degree of sensitivity ls lost. It san theretore be expected thet the actual channel spacing varition ir sowewht less than indicated in this report.

There are three coralusions to be dran from this olase of the evaluston: (1) pressure bonded subassembles have sufficienty uniform chamel specing to necessitse a more accurately probing method, (2) the subassembly chanel sparing vardation, Ior the 20 - long units in ceneral, occupled oniy loout $1 / 3$ of the range allowed for PWR and (3) the com ponent tolerances are aparenty whll balanced with the proces becure all sourees of 
channel spacing variation (channel averages, track averages within channels, and local polnts along tracks) contribute approximately the same amount to the total subassembiy variation.

\section{Corrosion Resistance}

Subascenbly AMC-1 was corrosion tested 3 days and MM-20-14 was tested 3 days, examined and returned to test for 25 additional days. Visual examination of MMcol disclosed, in addition to the normal shiny black corrosion film, a duI black corrosion film which covered aoproximately $1 \%$ of the total heat iransfer area. The dull area probably resulted from incomplete removal of the chromium used to plate the if -namel spacers to prevent diffusion of iron into zirconium. Fxamination of the heat transfer surfaces by oanoranac camera verified the oresence of the dull black film and disclosed no other defects. Visual examina

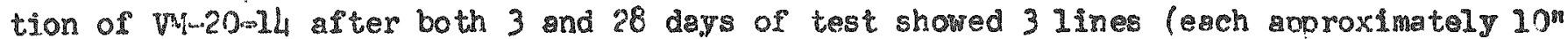
long) containing a white corrosion orodunt which apparently was bont line corrosion from incomplete bondine of the onter edge. No duIl areas were detected visually. The cause of the white corroston produch, whether unbond or a surface las or seam, is being investigated to determine the rause and extend of the defect.

Bond Integri ty

Bond integrity was evaluatad metallographically, radiographically and ultrasonically. MMG-1 was sectioned to remove the individual fuel plates for toray and ultrasonic tests. There was no evidence of unbonding in any of the plates on the $x \rightarrow r a y$ film and the uItrasonic test, which was ealibrated to datect unbonded areas $1 / 16$ "diameter or $12 r g e r$, diselosed no unbonded areas.

Five sections were cut Irom assembly AMG 1 and three sections were cut from assembly Wi-20-2 for metallogranic examination. All of the bonds appeared complete at 4 no: using bright field illumination, however, re-examination of the bonds with polarized llght revealed that certain of the fuel colad interiaces contained incomolete grain growth. In all of the areas exmined under polarized light, there was complete grain growth across zircaloy 2 Zircaloy 2 interfaces. The signifirance of sncomolete grain frowth has not yet been determined but will be investigated on the basis of comparson with equivalent bonds in rolled ruel alements. 
COMPONEYTS OF VARTANCF.

- Channel Spacing -

Source of Varition

Anong Channel Averages

Among Track Averages (within channels)

Among Local points (within tracks)

Standard Deviation in Mils.
AMGo 1 Plekled

\subsection{5}

0.53

0.81

\begin{tabular}{ll}
\multicolumn{2}{c}{ Me-20-14 } \\
Asonded & Plekled \\
0.53 & 0.63 \\
0.81 & 0.76 \\
0.53 & 0.63
\end{tabular}

TI $-20-2$

As Bonded

0.69

0.61

0.44

0.63

\section{PABL III}

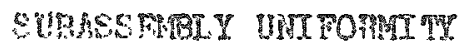

- Charnal spacing

Source of Varietion

M1 Track Mverages

11. Ghannel Avarges

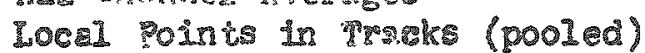

Iocal Points in chanels (pooled)

A1 Local points in subassembly
APring

toinged

$\stackrel{\tan 1 .}{-}$

0.852 .9

$0.75 \quad 3.5$

$0.82 \quad 2.3$

0.892 .5

1.273 .5
Fin-20.2 As: 2 nnced

$\therefore \quad$ tol.

0.832 .9

$0.69 \quad 3.3$

$0.44 \quad 1.2$

$0.68 \quad 1.9$

0.932 .6

Standard devlation and tolerance (99/99\%) in mis.

* There $1999 \%$ confldence that $99 \%$ of the $10 c a l$ points (or averages) are with in the average the tolerance. 